\title{
EL PODER DE LA NOBLEZA EN LOS ÁMBITOS REGIONALES DE LA CORONA DE CASTILLA A FINES DEL MEDIEVO: LAS ESTRATEGIAS POLÍTICAS DE LOS GRANDES LINAJES EN LA RIOJA HASTA LA REVUELTA COMUNERA
}

\section{MÁXimo Diago HeRnANDo}

Instituto de Historia. CSIC. Madrid

RESUMEN: En las últimas décadas del siglo XV y las primeras del siglo XVI el territorio de la Rioja fue escenario de un permanente y violento conflicto entre tres linajes de alta nobleza-Manrique, Arellano y Velasco-por alcanzar la hegemonía en la región. Este hecho pone de manifiesto las limitaciones del éxito de los Reyes Católicos en su empresa de pacificación del reino y de sometimiento político de la nobleza. Abundando en la demostración de esta tesis, en este artículo se analizan las estrategias a las que recurrieron estos tres linajes de alta nobleza para incrementar la capacidad de ejercicio del poder en el ámbito regional riojano que les proporcionaba el control de sus propios estados señoriales. Para ello se da cuenta de sus relaciones con los nobles de rango medio señores de vasallos de la región, con los monasterios y otras instituciones eclesiásticas, $y$ con las ciudades realengas.

Palabras clave: Castilla. Rioja. Alta Nobleza. Bandos Nobiliarios. Siglo XV. Siglo XVI.

ABSTRACT: During the last decades of the fifteenth century and the first decades of the sixteenth, a permanent and violent struggle for hegemony took place in the region of Rioja between three families of the high nobility - the Manrique, the Arellano and the Velasco. This indicates that King Ferdinand and Queen Isabella's success in pacifying the kingdom and in the political subjection of the high nobility was very limited. To provide a more detailed demonstration of this thesis, this article analyses the strategies employed by these three lineages of the high nobility to increase their power in Rioja where they possessed their seigneurial estates. Consideration is given to their relationships with nobles of middle rank who were lords of vassals in the region; with monasteries and other ecclesiastical institutions; and finally with royal towns.

KEY WORDS: Castile. Rioja. High Nobility. Noble factions. Fifteenth century. Sixteenth century. 
El gran número de trabajos de investigación y síntesis dedicados en la segunda mitad del siglo XX a la reconstrucción e interpretación de la historia política de la Corona de Castilla durante los siglos bajomedievales ha puesto suficientemente de manifiesto el papel central que aquí desempeñaron en el ejercicio del poder los linajes de alta nobleza durante este período. Se ha de tener en cuenta, no obstante, que tales linajes hicieron uso entonces de su capacidad de ejercicio del poder en muy diversos niveles, y no todos ellos han atraído hasta ahora en igual manera la atención de los investigadores.

Por un lado se ha prestado bastante atención al nivel superior, que con el transcurso de los siglos fue adquiriendo una creciente importancia, conforme se avanzó en la articulación política del reino y se fortalecieron las instancias centrales de gobierno del territorio en su conjunto. Es el que convencionalmente denominamos nivel de gobierno central, que abarcaba al conjunto de instituciones por medio de las cuales los monarcas soberanos ejercían de forma directa, y no por delegación, sus funciones de gobernantes y dispensadores de justicia, el cual en la época medieval se concretaba en el espacio físico donde se encontraba el monarca en cada momento, convencionalmente identificado con el nombre de Corte ${ }^{1}$. Para participar en el ejercicio del poder en este nivel los miembros de la alta nobleza tenían por tanto que moverse en el entorno personal del rey, y seguirle en sus desplazamientos, asumiendo el papel de sus consejeros, aunque, por supuesto, no era necesario que permaneciesen todo el tiempo en la Corte, sino que bastaba con que estuviesen presentes en ella cuando se habían de tomar las decisiones políticas de más trascendencia, para lo cual podían incluso llegar a ser convocados personalmente por los monarcas.

No es nuestra intención detenernos aquí en dar cuenta de los rasgos peculiares del modelo de participación en el ejercicio del poder por los miembros de la alta nobleza castellana en este nivel, entre otras razones porque, como hemos adelantado, se trata de uno de los aspectos de la historia política castellana a los que más atención han prestado los investigadores durante la segunda mitad del siglo XX. Hubo otros niveles en los que estos mismos nobles alcanzaron un destacado protagonismo en el ejercicio del poder que merecen también la atención del historiador, pero a los que hasta ahora se ha prestado menor atención. Es el caso del «nivel local», es decir, aquél en el que el poder se ejercía de forma cotidiana sobre el conjunto de habitantes de un núcleo de población determinado, o de varios núcleos que formaban una unidad desde el punto de vista jurisdiccional. El análisis de los mecanismos de ejercicio del poder en este nivel requiere tener en cuenta una multitud de variables, relacionadas con las peculiaridades de les estructuras sociopolíticas de las distintas localidades en parti-

${ }^{1}$ De la abundante bibliografía dedicada al estudio de la Corte en los reinos hispanos bajomedievales se pueden destacar los recientes trabajos de FERNÁNDEZ DE CóRDOVA MiralLES, Álvaro: La Corte de Isabel I. Ritos y ceremonias de una reina (1474-1504), Madrid, Dykinson, 2002. Y Costa Gomes, Rita: Kings and Nobles in Late Medieval Portugal, Cambridge, Cambridge University Press, 2003. 
cular, y por ello sólo resulta posible avanzar en su conocimiento mediante la realización de un gran número de monografías de historia local. Y lo cierto es que en las últimas décadas los investigadores también han avanzado de forma apreciable en este terreno, pues han sido legión los trabajos que se han dedicado al estudio del ejercicio del poder en lugares de señorío de los más diversos ámbitos de la Corona de Castilla, sobre todo desde la perspectiva del análisis de los estados señoriales de la nobleza como «espacio de poder» ${ }^{2}$.

Entre estos dos niveles extremos de ejercicio del poder, el central y el local, se pueden distinguir, no obstante, otros de carácter intermedio que, por su mayor complejidad, han merecido en líneas generales menor atención de los investigadores. Son los que podemos denominar «niveles regionales», delimitables conforme a múltiples criterios, en los cuales los nobles podían ejercer el poder por muy diversas vías, tanto legítimas como ilegítimas. Por poner un ejemplo, podían hacerlo legítimamente si habían sido nombrados por los reyes como sus representantes para el ejercicio de su autoridad por delegación en un ámbito territorial determinado, con el título de merinos o adelantados ${ }^{3}$. Pero también podían servirse de procedimientos de carácter más irregular para, desde las bases que les proporcionaban sus propios señoríos, extender su radio de influencia sobre territorios más o menos amplios que no estaban sometidos directamente a su jurisdicción.

Gracias a trabajos pioneros como el que a comienzos de la década de 1970 dedicó el profesor M.A. Ladero Quesada a la historia política de Andalucía en el siglo $\mathrm{XV}^{4}$, se ha podido constatar cómo durante este convulso período de la historia castellana determinados linajes de alta nobleza aspiraron a reservarse el control político de regiones concretas del reino, aunque tropezaron con grandes dificultades para conseguirlo, más que por las resistencias ofrecidas desde el poder central, por razón de la propia competencia en que entraron con otros linajes que tenían las mismas aspiraciones que ellos. Por supuesto no todas las regiones de la Corona de Castilla experimentaron entonces una idéntica evolu-

\footnotetext{
${ }^{2}$ Una reciente visión de conjunto sobre esta cuestión en QUiNTANILla RASO, Ma . C.: «El estado señorial nobiliario como espacio de poder en la Castilla bajomedieval», Los espacios de poder en la España Medieval, Logroño, Instituto de Estudios Riojanos, 2002, pp. 245-314.

3 Una monografía que presta atención a esta faceta del ejercicio del poder por los linajes de la alta nobleza en el ámbito geográfico del reino de León es la de JULAR PÉREZ-AlFARO, Cristina: Los adelantados y merinos mayores de León (Siglos XIII-XV), León, 1990. Para el reino de Castilla no se dispone de ningún trabajo enfocado desde esta perspectiva, aunque sí existen trabajos dedicados al análisis de la figura institucional de los adelantados, entre los que destaca el de PÉrEZ Bustamante, Rogelio: El gobierno y la administración de los reinos de la Corona de Castilla (12301474), Madrid, 1976. Para un período posterior, en que la nobleza ya no pudo servirse de las instituciones de los adelantamientos para el ejercicio personal del poder, interesa el trabajo de Arregui. Zamorano, Pilar: Monarquía y señoríos en la Castilla moderna: Los Adelantamientos de Castilla, León y Campos. 1474-1643, Valladolid, Junta de Castilla y León, 2000.

${ }^{4}$ Ladero Quesada, Miguel Ángel: Andalucía en el siglo XV. Estudios de bistoria política, Madrid, CSIC, 1973.
} 
ción, sino que, a juzgar por los resultados de los trabajos de investigación dados a conocer hasta el momento, hubo unas en que la capacidad de control del territorio por parte de la monarquía fue mayor, y otras en que la nobleza consiguió ejercer un dominio casi absoluto. Desde una perspectiva global, no obstante, puede afirmarse que en determinados momentos del siglo XV, la Corona de Castilla estuvo bastante cerca de quedar reducida a una suerte de federación de regiones sometidas al dominio de la nobleza. Pero esta situación no tuvo entonces carácter excepcional puesto que incluso en otros territorios europeos en que la monarquía consiguió dotarse muy tempranamente de eficaces instrumentos para el ejercicio de su autoridad, como es el caso de Inglaterra, también ha podido constatarse en los siglos bajomedievales una evolución de parecido signo ${ }^{5}$.

No obstante, aunque la amenaza de disgregación llegó a alcanzar notoria gravedad en determinados momentos del reinado de Enrique IV, el proceso no fue llevado a sus últimas consecuencias, sino que, antes al contrario, después de la muerte de este monarca y la consolidación en el trono, tras varios años de guerra civil, de su hermana Isabel la Católica, fue radicalmente frenado gracias a que la monarquía consiguió imponerse sobre la nobleza levantisca, y dio pasos decisivos para asegurarse de que sus decisiones eran acatadas en todo el territorio sometido a su autoridad.

En efecto, los Reyes Católicos, además de trasladarse en persona a las regiones de la Corona donde la autoridad de la monarquía se encontraba menos arraigada, y en contrapartida la nobleza había ejercido un dominio casi absoluto en el período previo a su acceso al trono, para con su presencia contribuir a hacerse respetar ${ }^{6}$, tomaron una serie de importantes medidas para recortar la capacidad de ejercicio del poder de los miembros de la alta nobleza en las regiones del reino donde se concentraban sus patrimonios señoriales. No es éste el lugar de relacionarlas, pero sí conviene al menos indicar que entre ellas destacaron la prohibición de que oficiales de los concejos de realengo «viviesen» con miembros de la alta nobleza, y llevasen de ellos «acostamientos», y la generalización del envío de corregidores, todopoderosos oficiales de designación regia que privaron a muchos nobles de la capacidad que habían tenido de controlar los oficios de la justicia en numerosas ciudades de realengo, entre las que se contaban las principales de la mitad meridional del reino.

\footnotetext{
${ }^{5}$ Autores como Given-Wilson y Bernard han llegado a calificar a la Inglaterra de los siglos XIV y XV como una «federación de esferas señoriales de influencia». No obstante este punto de vista extremo se ha visto parcialmente cuestionado en los últimos tiempos, al haberse podido comprobar que no en todas las regiones hubo magnates residentes que dominasen su vida política. Vid. Hicks, Michael: Bastard Feudalism, London-New York, Longman, 1995, p. 156.

${ }^{6}$ Sobre la importancia de la presencia regia como factor de pacificación y reforzamiento de la autoridad de la monarquía frente a la nobleza ha llamado recientemente la atención, refiriéndose al caso concreto de la ciudad de Toledo al comienzo del reinado de los reyes Católicos, López Gómez, Óscar: "Claves del sistema de pacificación ciudadana desarrollado por los Reyes Católicos en Toledo (1475-1485)», En la España Medieval, 27 (2004), pp. 165-193, en especial pp. 186 y ss.
} 
La efectividad de estas medidas fue en un primer momento grande en bastantes ciudades que durante gran parte del siglo XV habían estado sometidas a un fuerte intervencionismo de los representantes de la alta nobleza, como es el caso, por ejemplo, de las andaluzas o de la ciudad de Toledo. Pero también es cierto que muchos indicios revelan que la prohibición impuesta a los oficiales de las ciudades de realengo de «vivir con señores» fue burlada con bastante frecuencia a todo lo largo y ancho de la Corona de Castilla, a pesar de que una y otra vez los monarcas la confirmaron mediantes cartas y sobrecartas. Y tras la muerte de la reina Isabel en noviembre de 1504 la situación experimentó un evidente deterioro, que se tradujo, por ejemplo, en numerosos intentos protagonizados por miembros de la alta nobleza de recuperar las parcelas de poder que ellos mismos o sus progenitores habían controlado en las principales ciudades realengas durante los años de gobierno de Enrique IV ${ }^{7}$.

En cualquier caso el éxito alcanzado por los Reyes Católicos en su empresa de limitar la capacidad de ejercicio del poder de los miembros de la alta nobleza en los ámbitos regionales del reino, fuera de sus señoríos, tampoco fue idéntico en todos y cada uno de dichos ámbitos, entre otras razones porque la situación de partida era muy diferente de unos a otros. Para llegar a conocer en detalle los resultados efectivos obtenidos por estos monarcas en su empresa de fortalecimiento del poder monárquico frente al poder nobiliario continúa resultando preciso por lo tanto dedicar esfuerzos a la realización de monografías de historia política regional, que permitan valorar mejor las capacidades efectivas de ejercicio del poder a escala regional que los distintos linajes de alta nobleza en particular mantuvieron en dicho período, tanto en vida de la reina Isabel como tras su muerte. Y esto es lo que nos hemos propuesto llevar a cabo en el presente trabajo, dedicando nuestra atención a un ámbito regional en el que el peso político de la alta nobleza continuaba siendo todavía muy grande a fines de la Edad Media, el de la Rioja.

Ciertamente el término Rioja es polisémico, y su utilización puede dar lugar a malentendidos y a proyecciones sobre el pasado de situaciones del presente, pero a pesar de ello, por comodidad, hemos optado por utilizarlo para referirnos al territorio fronterizo con el reino de Navarra, cuya representación en Cortes se repartieron, desde el siglo XV y hasta el final del Antiguo Régimen, las ciudades de Burgos y Soria, que a grandes rasgos coincide con el que en la actualidad abarca la comunidad autónoma riojana, aunque también incorpora

\footnotetext{
${ }^{7}$ Resultan bien conocidos los casos de Córdoba, Toledo y Cuenca. Sobre el caso de Córdoba vid. EDWARds, John: Christian Cordoba. The city and its region in the Late Middle Ages, Cambridge, Cambridge University Press,1982, pp. 157 y ss. Y, «La révolte du marquis de priego à Cordove», Mélanges de la Casa de Velázquez, 12 (1976), pp. 165-172. Sobre Cuenca Vid. Diago Hernando, Máximo: «La alta nobleza en la vida política de las ciudades castellanas en las décadas precomuneras: el ejemplo de Cuenca (1506-1507)», Cuadernos de Historia Moderna, 15 (1994), pp. 121-41. Y sobre Toledo, Palencia Herrejón, José Ramón: Los Ayala de Toledo. Desarrollo e instrumentos de poder de un linaje nobiliario en el siglo XV, Toledo, Diputación Provincial, 1995, pp. 89 y ss.
} 
otras tierras de las actuales provincias de Soria y Burgos, que a fines de la Edad Media mantenían fuertes vínculos políticos con las tierras que hoy forman parte de dicha comunidad autónoma, al estar integradas dentro de unos mismos estados señoriales, como eran, por ejemplo, los de los Arellano, condes de Aguilar, y los Manrique, duques de Nájera.

Efectuada esta aclaración de carácter terminológico, y habiendo dejado sentado que la región de que vamos a hablar tiene unos límites difusos, y no constituía en la época analizada una entidad territorial diferenciada, dotada de identidad propia, no estará de más que llamemos la atención aquí sobre algunos de sus principales rasgos definitorios, que justifican que la hayamos escogido para llevar a cabo una monografía del tipo de la que proponemos. En primer lugar hemos de destacar que se trataba de una región caracterizada por una extrema fragmentación jurisdiccional, que contrastaba con la existencia de compactos bloques jurisdiccionales en las comarcas que se extendían por su flanco sur, como era el caso, por ejemplo, de la Tierra de Soria. En principio esta fragmentación no favorecía la concentración del poder en unas pocas manos, sino todo lo contrario. Y de hecho no fue inusual que en un mismo lugar varias instancias compartiesen el ejercicio de la jurisdicción sobre la población en él residente. Pero también hay que tener en cuenta que una determinada instancia, ya se tratase de un noble, un monasterio o una ciudad, podía llegar a acumular derechos sobre múltiples lugares que no estaban unidos entre sí por ningún tipo de vínculo jurisdiccional, y sólo tenían en común la dependencia respecto a un mismo señor. Y, en efecto, así ocurrió, de modo que también en esta región, pese a su notable fragmentación jurisdiccional, se llegaron a constituir grandes estados señoriales. Pero, a diferencia de los que se consolidaron al sur de la línea del Duero, estos estados raramente llegaron a conformar compactos bloques territoriales, sino que presentaron una marcada tendencia a la dispersión, y además estuvieron muy compartimentados, no sólo por razones geográficas sino también como consecuencia de la falta de vínculos jurisdiccionales entre los distintos lugares que los integraban.

Como comprobaremos más en detalle en los siguientes epígrafes, en la Rioja fueron titulares de derechos señoriales instancias muy diversas, desde corporaciones urbanas hasta instituciones eclesiásticas, pasando por nobles de muy diverso rango, y además hubo, por supuesto, territorios integrados en el realengo, y unos pocos señoríos de behetría ${ }^{8}$. Pero con el transcurso de los siglos se produjo una notable expansión de los estados señoriales en manos de linajes de alta nobleza, en detrimento de todos los demás. Y esta evolución propició que el equilibrio de fuerzas en la región terminase rompiéndose decididamente en

${ }^{8}$ Los señoríos de behetría de la Rioja resultan en general muy mal conocidos, entre otros motivos porque en el Libro Becerro del año 1352 no se han conservado los datos correspondientes a las merindades de Rioja-Montes de Oca, Nájera, Logroño y Cameros-Río Iregua. Ninguna referencia a ellos se puede encontrar en la última gran monografía dedicada al estudio de este tipo de señoríos, la de Estepa DíEZ, Carlos: Las behetrías castellanas, Valladolid, Junta de Castilla y León, 2003. 
favor de este grupo sociopolítico, en detrimento de las ciudades realengas, que apenas lograron avances significativos en la ampliación de sus señoríos territoriales, y de los grandes monasterios, como San Millán de la Cogolla y Santa María de Nájera, que en los siglos plenomedievales habían sido los que mayor número de vasallos habían tenido bajo su dependencia, salvando quizás a los señores de Cameros, aunque ejercían sobre ellos un tipo de señorío que podemos calificar como «débil», por sus grandes limitaciones, y que además fue muy contestado por los propios vasallos.

Ciertamente la Rioja fue una región muy urbanizada, sobre todo en su sector septentrional más próximo al río Ebro, donde prosperaron, gracias en parte al impulso proporcionado por el Camino de Santiago, varios núcleos con dinámicos grupos de mercaderes y financieros, que se contaron entre los más activos del norte de Castilla, como fueron Santo Domingo de la Calzada, Nájera, Haro, Logroño, Calahorra y Alfaro. Pero este dinamismo que en el terreno económico mostraron las ciudades riojanas no tuvo su traducción en el terreno político, puesto que, aunque es cierto que varias de ellas se esforzaron por ampliar sus bases para el ejercicio del poder en la región mediante la adquisición de derechos señoriales sobre lugares de su entorno, no llegaron ni de lejos a conseguir labrarse señoríos de la importancia de los que en los siglos bajomedievales reunieron ciudades como Burgos o Valladolid, que tenían un peso político en el reino mucho mayor ${ }^{9}$. La falta de éxito en esta empresa de ampliar significativamente el territorio sobre el que ejercían jurisdicción, unida al hecho de que los términos que tuvieron asignados en origen todas estas ciudades fueron muy cortos, dejó un legado de debilidad a las corporaciones de gobierno de las ciudades riojanas, que les impidió competir en términos de igualdad con los grandes linajes de alta nobleza por alcanzar la hegemonía política en la región, sobre todo a partir del período Trastamara, cuando quedaron allí consolidados los grandes estados señoriales nobiliarios que pervivieron hasta el siglo XVIII.

Todas estas circunstancias que de modo somero hemos mencionado, y otras más de las que iremos dando cuenta a lo largo de nuestra exposición, confirieron a la vida política regional en la Rioja una serie de peculiaridades que justifican el que se le dedique un estudio particularizado, desde la perspectiva de la evolución de las estrategias de ejercicio del poder de los linajes de alta nobleza en los ámbitos regionales de la Corona de Castilla. Ésta es la tarea que trataremos de llevar a cabo en el presente trabajo, tomando como marco de referencia cronológico el período que va desde el acceso al trono de los Reyes Católicos

9 Vid. Bonachía Hernando, José Antonio: El señorío de Burgos durante la Baja Edad Media (1255-1508), Valladolid, 1988. Y, «El concejo como señorío (Castilla, siglos XIII-XV)», en Concejos y ciudades en la Edad Media hispánica. II. Congreso de Estudios Medievales, León, Fundación Sánchez Albornoz, 1990, pp. 431-463. Visión general sobre los señoríos territoriales de las ciudades castellanas bajomedievales, puestos en comparación con los de las alemanas en DiAGo HerNANDO, Máximo: «Los señoríos territoriales de las ciudades europeas bajomedievales. Análisis comparativo de los ejemplos castellano y alemán», Hispania, 188 (1994), pp. 791-844. 
hasta el estallido de la revuelta comunera. No es nuestro propósito, sin embargo, reconstruir de forma sistemática y pormenorizada la evolución de la vida política regional en estas cuatro largas décadas, sino que sólo nos ocuparemos de la identificación de los procedimientos y estrategias a que recurrieron los principales representantes de la alta nobleza en la región para ampliar la capacidad de ejercicio del poder que les proporcionaban sus propios señoríos.

\section{LOS GRANDES ESTADOS SEÑORIALES COMO PLATAFORMA PARA EL EJERCI- CIO DEL PODER POR LOS LINAJES DE ALTA NOBLEZA}

Como ya hemos avanzado, la notable fragmentación en pequeñas unidades jurisdiccionales que caracterizó al espacio abarcado por las merindades de Rioja, Nájera, Logroño y Cameros-Río Iregua, no ofrecía condiciones favorables para la consolidación de grandes estados señoriales en dicho territorio. No obstante los linajes de alta nobleza sí que tuvieron una fuerte presencia política en él desde fechas bastante tempranas, y algunos llegaron a reunir un patrimonio señorial bastante importante, como es el caso de los señores de Cameros, del linaje de los Fortuniones, primero, y del de los Haro, después ${ }^{10}$. Tras el ajusticiamiento de Juan Alfonso de Haro por orden de Alfonso XI en 1333 se produjo, sin embargo, un importante eclipse del poder nobiliario en la región, abriéndose un intermedio al que puso fin la consolidación en el trono castellano de Enrique de Trastamara, puesto que bajo el gobierno de la nueva dinastía tuvo lugar en la Rioja, al igual que en el conjunto de la Corona de Castilla, la consolidación de nuevos grandes señoríos nobiliarios.

Bien conocido resulta en casi todos sus detalles el proceso de constitución en tierras riojanas del estado señorial del linaje Arellano, a partir del antiguo señorío de los Cameros ${ }^{11}$, por lo cual no vamos a detenernos aquí en dar cuenta de él, limitándonos a hacer constar que no sólo propició la acumulación de un elevado número de lugares de señorío en manos de la rama primogénita del linaje, la de los condes de Aguilar, sino que también hizo posible que varias ramas de segundones se hiciesen con la propiedad de pequeños señoríos en esta misma región, desde los que mantuvieron unas relaciones políticas contradictorias con sus parientes mayores, en unas ocasiones de estrecha colaboración y en otras de enconado enfrentamiento.

10 .Sobre este señorío Vid. Diago Hernando, Máximo: «Los Haro de Cameros en los siglos XIII y XIV. Análisis del proceso de su afianzamiento político en el ámbito regional», Anuario de Estudios Medievales, 24 (1994), pp. 775-806.

11 Vid. Moreno Ramírez De Arellano, Miguel Ángel: Señorío de Cameros y condado de Aguilar. Cuatro siglos de régimen señorial en La Rioja (1366-1733), Logroño, 1992. GONZÁLEZ CRESPO, Esther: «Los Arellano y el señorío de los Cameros en la Baja Edad Media», En la España Medieval, II, Madrid, 1982, vol. I, pp. 395-410. Y, DiAGO HERNANDO, Máximo: «Implantación territorial del linaje Arellano en tierras camero-riojanas a fines de la Edad Media», Berceo, 120 (1991), pp. 65-82. 
La rama primogénita de los Arellano, titular del señorío de Cameros, y a partir del reinado de los Reyes Católicos también del título del condado de Aguilar, consiguió labrarse un estado señorial de muy heterogénea composición, sin duda muy fragmentado desde el punto de vista jurisdiccional, pero que en contrapartida presentaba la particularidad de estar en su mayor parte concentrado en una única región de la Corona de Castilla, la de la Rioja, puesto que fuera de la misma sólo poseyó de forma continuada un territorio de cierta importancia, la Tierra de Fuentepinilla, en la actual provincia de Soria, que por lo demás tampoco se encontraba muy alejado del resto de los señoríos.

Esta concentración geográfica de su estado señorial en la región riojana propició que durante todo el siglo XV y las primeras décadas del siglo XVI los Arellano tuviesen fijados sus intereses políticos de forma prácticamente exclusiva en este territorio, que además les proporcionaba una plataforma adecuada para poder continuar interviniendo en los asuntos de su reino de origen, Navarra, que aprovecharon en ocasiones, aunque no de forma continuada y sistemática $^{12}$. Y desde esta perspectiva representaron un caso excepcional entre los linajes de alta nobleza que poseyeron señoríos en la región, puesto que todos los demás contaron con grandes señoríos ubicados fuera de la Rioja, en ocasiones en ámbitos muy alejados, como era, por ejemplo, Extremadura, y por consiguiente tuvieron mucho más diversificados sus intereses políticos en varias regiones de la Corona.

Éste fue el caso, por ejemplo, de los Manrique, que en su rama principal, la de los condes de Treviño y duques de Nájera, llegó a reunir a fines del siglo $\mathrm{XV}$ un importante patrimonio señorial en la región objeto de estudio, en el que se incluían villas con una pujante ganadería trashumante, como Lumbreras, Villoslada y San Pedro de Yanguas, luego llamado San Pedro Manrique, en la actual provincia de Soria, otras con gran potencial agrícola, como Navarrete y Ocón, y, por fin ciudades con notable relevancia mercantil y política, como era el caso de Nájera, núcleo cabecera de merindad ${ }^{13}$. Pero, con ser importante el patrimonio señorial de esta rama de los Manrique en la Rioja, lo cierto es que poseyó otros muchos señoríos de tanta o mayor importancia en otras regiones de la Corona de Castilla, como, por ejemplo, en la actual provincia de Palencia,

\footnotetext{
12 Algunas noticias sobre la intervención de los Arellano de Cameros en la vida política interna de Navarra en el siglo XV y primeras décadas del siglo XVI en Diago Hernando, Máximo: «Política y guerra en la frontera castellano-navarra durante la época Trastamara», Príncipe de Viana, 203 (1994), pp. 525-48.

${ }_{13}$ Una reciente visión general sobre la trayectoria histórica en los siglos bajomedievales del linaje Manrique en sus diversas ramas en Montero TejADA, Rosa María. Nobleza y sociedad en Castilla. El linaje Manrique (Siglos XIV-XVI), Madrid, Caja Madrid, 1996. En esta obra, no obstante, no se analiza con detalle el proceso de constitución del estado señorial de los Manrique en la Rioja y comarcas adyacentes, algunos aspectos del cual siguen resultando mal conocidos. De gran utilidad para el seguimiento de la trayectoria política del linaje sigue resultando la obra clásica de SAlAZAR y CASTRO, Luis de: Historia genealógica de la Casa de Lara, Madrid, 1697.
} 
donde sus sucesivos representantes también desplegaron una intensa actividad política encaminada a ampliar sus bases de ejercicio del poder a escala regional, entrando curiosamente en colisión por este motivo con otro linaje con el que también chocaron en Rioja, en concreto el de los Velasco.

En comparación con los Arellano y con los Manrique, los Velasco tuvieron en la Rioja un patrimonio señorial de menor envergadura, y, sobre todo, el peso de sus señoríos riojanos en el conjunto de su estado señorial era de carácter más decididamente secundario, al concentrarse sus principales posesiones en otros ámbitos, en particular en las actuales provincias de Burgos y Palencia. Pero esta circunstancia, sin embargo, no impidió que mostrasen un decidido interés por participar activamente en la vida política de esta región, y por ampliar en la medida de sus posibilidades sus bases para el ejercicio del poder en la misma. Y ocurrió así en gran medida como consecuencia de su encarnizada rivalidad con los Manrique, condes de Treviño, y luego duques de Nájera, que les arrastró a entrar en conflicto con ellos también en el territorio riojano, que ofrecía un indiscutible valor estratégico como puente hacia Navarra y las provincias vascongadas, territorios ambos hacia donde estos dos linajes también trataron de extender su radio de influencia, entrando por consiguiente en conflicto el uno con el otro.

Por otra parte, aunque la Rioja no era el ámbito donde se concentraba la mayor parte del patrimonio señorial del linaje Velasco, tampoco podemos perder de vista que éste llegó a hacerse con el control en esta región de algunos enclaves de notable valor estratégico y político, como era en concreto el caso de la ciudad de Haro, en la Rioja Alta, y en menor medida también de la de Arnedo, en la Rioja Baja, que quedó adscrita a una rama menor, la de los condes de Nieva, en la que se mezclaba la sangre de los Velasco con la de los Estúñiga.

La trayectoria en la Rioja del linaje de los Estúñiga, que al igual que los Arellano eran también de origen navarro, presentó la particularidad de que, aunque fue de los primeros en arraigar en esta región, que le sirvió de trampolín para integrarse en la sociedad política castellana ${ }^{14}$, conforme fue ascendiendo y adquiriendo señoríos de mayor importancia en otras regiones de la Corona de Castilla fue perdiendo interés por participar activamente en la vida política regional riojana, hasta llegar a desinteresarse de forma prácticamente total por la misma, haciendo excepción de sus representantes de la ya referida línea de los condes de Nieva, señores de la villa de Arnedo, en los que, no obstante, fluía también la sangre de los Velasco, que explica su militancia en el bando de los Condestables de Castilla y condes de $\mathrm{Haro}^{15}$.

${ }^{14}$ Sobre el paso a Castilla de los Estúñiga Vid. Villalobos y Martínez Pontremuli, M ${ }^{\mathrm{a}}$. Luisa: «Los Estúñiga. La penetración en Castilla de un linaje de la nobleza nueva», Cuadernos de Historia. Anexos a la Revista Hispania, 6 (1975), pp. 327-57. Sobre sus señoríos en la Rioja vid. LorA SERrANo, Gloria: «Propiedades y rentas de la Casa de Estúñiga en la Rioja», Anuario de Estudios Medievales, 19 (1989), pp. 469-83.

15 Sobre esta cuestión Vid. Diago Hernando, Máximo: «Linajes navarros en la vida política de la Rioja bajomedieval. El ejemplo de los Estúñiga», Príncipe de Viana, 197 (1992), pp. 563-81. 
$\mathrm{Al}$ margen de los linajes indicados, cabría mencionar algunos otros que llegaron a poseer pequeños señoríos en la región riojana, como es el caso de los de La Cerda, condes y luego duques de Medinaceli, que poseyeron Enciso tras el matrimonio de Juana de Sarmiento, señora de la villa, con el conde Luis de la $\mathrm{Cerda}^{16}$. Ciertamente este linaje se contaba también entre los principales del reino, y en una región vecina de la riojana, la que tenía su capital en la ciudad de Soria, alcanzó durante el siglo XV un notable protagonismo en la vida política. Pero en la Rioja su patrimonio señorial resultaba manifiestamente insuficiente para sustentar sobre él un ambicioso proyecto orientado a lograr su consolidación como un poder político regional. Y, por consiguiente, sus principales representantes se abstuvieron de participar activamente en los asuntos internos de la región, hasta el punto de que en alguna ocasión llegaron incluso a ceder el control de esta villa a los Arellano, señores de Cameros, por considerar que éstos podrían garantizar mejor su seguridad. Así ocurrió, por ejemplo, en 1441, según consta por una carta del conde Luis de la Cerda dirigida al concejo de Enciso, ordenándole que admitiese a Juan Ramírez de Arellano, señor de Cameros, cuando fuese a tomar posesión de la villa y su fortaleza ${ }^{17}$.

En suma, por tanto, en las últimas décadas del siglo XV y primeras del siglo XVI, período en que vamos a centrar nuestro estudio, los tres principales linajes que rivalizaron por la hegemonía en la región fueron los de Arellano, Velasco y Manrique, puesto que los Estúñiga, que habían alcanzado un notorio protagonismo en la primera mitad del siglo XV, cuando un miembro del linaje ocupó la sede calagurritana, se eclipsaron como consecuencia de que sus principales representantes, los duque de Béjar, desplazaron hacia otras regiones de la Corona de Castilla sus ambiciones políticas.

\section{LOS ABUSOS DE PODER POR LOS MIEMBROS DE LA ALTA NOBLEZA EN SUS SEÑORÍOS RIOJANOS DURANTE EL REINADO DE LOS REYES CATÓLICOS}

Los estados señoriales en la Castilla bajomedieval y moderna no eran «agujeros negros» en los que los señores pudiesen ejercer de forma arbitraria el poder, sin quedar sometidos a ningún tipo de control. Por el contrario, las limitaciones que la ley imponía a los titulares de derechos jurisdiccionales en su capacidad de ejercicio del poder sobre la población residente en sus señoríos eran grandes, y las instituciones de administración de justicia de la monarquía

\footnotetext{
16 Sobre el proceso de incorporación de Enciso al mayorazgo de los duques de Medinaceli, que no culminó hasta 1502, Vid. DiAGO HERNANDO, Máximo: La Extremadura soriana y su ámbito a fines de la Edad Media, Madrid, Universidad Complutense, 1992, p. 108.

17 Publica el documento Pardo RodríGueZ, $\mathrm{M}^{\mathrm{a}}$. L.:Documentación del Condado de Medinaceli (1368-1454), Soria, Diputación Provincial, 1993, doc. nº 178. Luis de la Cerda justifica su decisión con el siguiente argumento: «Por cuanto la villa está apartada de donde yo estó, e non me cabe en comarca, e según los tiempos que están, no os podría socorrer como querría».
} 
estaban para garantizar que lo que disponía la ley se cumplía, al tener abierta todos los vasallos de señorío la posibilidad de recurrir a ellas para denunciar los posibles abusos cometidos contra ellos por sus señores, y exigir el correspondiente desagravio.

En la práctica, sin embargo, la capacidad de estas instituciones para ofrecer protección a la población que vivía bajo el régimen señorial fue en ocasiones muy limitada. Y, según denuncias que encontramos reiteradamente en la documentación, así ocurrió durante gran parte del reinado de Enrique IV, en especial en su segunda mitad. La llegada al trono de los Reyes Católicos vino acompañada por un singular esfuerzo para devolver credibilidad a la imagen de la monarquía como eficaz dispensadora de justicia para todos los súbditos del reino, incluidos los que residían en lugares de señorío. Con este objeto fueron potenciados los tribunales centrales, en particular las Chancillerías y el Consejo Real, pero también otras instituciones que operaban en el nivel territorial, como fue el caso de los alcaldes de los Adelantamientos de Castilla y León, por medio de los cuales, según se ha demostrado en la tesis de Pilar Arregui Zamorano, se trató de hacer accesible la justicia del rey a los numerosos súbditos de la Corona que residían en comarcas rurales del tercio norte peninsular, sometidas al régimen señorial ${ }^{18}$.

A pesar de los importantes logros alcanzados, los Reyes Católicos, sin embargo, continuaron tropezando con graves dificultades para conseguir erradicar las prácticas de abuso de poder que tanto se habían extendido en los territorios sometidos a régimen señorial durante los prolongados períodos de inestabilidad por los que atravesó la Corona de Castilla a lo largo del siglo XV. Y estas dificultades se plantearon con especial gravedad en determinadas regiones, entre las que figuró, según trataremos de demostrar a continuación, la de la Rioja, como consecuencia del extraordinario poderío que allí habían logrado acumular algunos representantes de la alta nobleza.

Un buen testimonio de esta realidad nos lo proporcionan las actuaciones de los Arellano, condes de Aguilar, en las Cinco Villas y Valdecanales, lugares que, después de haber formado parte transitoriamente del realengo durante los reinados de Alfonso XI y Pedro I, habían sido cedidos por Enrique II a su fiel compañero de armas Juan Ramírez de Arellano, como parte integrante del señorío de Cameros ${ }^{19}$. Según denunciaron en repetidas ocasiones los vecinos de estas villas, sus señores les habían tenido sojuzgados durante gran parte de los reinados de Juan II y de Enrique IV, imponiéndoles todo tipo de «fuerzas, temores, miedos y presiones», no habiéndose atrevido entonces a presentar queja formal ante la monarquía de los agravios sufridos por miedo, pues si en alguna ocasión alguien había osado hacerlo había sido arrojado a las mazmorras de

18 Vid. Arregui. Zamorano, Pilar: op. cit.

19 Vid. Diago Hernando, Máximo: «Los Haro de Cameros...». Y «Un noble entre tres reinos en la España del siglo XIV: Juan Ramírez de Arellano», Príncipe de Viana,230 (2003), pp. 523-56. 
algún castillo señorial, y se le había sometido allí a todo tipo de tratos injuriosos. Tras la llegada al trono de los Reyes Católicos estos atribulados vasallos recuperaron, no obstante, cierta confianza en la capacidad de la institución de la monarquía para liberarles de la opresión en la que habían vivido en los tiempos en que en todo el reino había existido tan notorio «defecto de justicia». Y por ello decidieron emprender entonces el camino de la batalla legal, presentando querella contra sus señores en los tribunales centrales de la monarquía, el Consejo Real y la Chancillería de Valladolid. En ambas instancias, en efecto, nos consta que estuvieron litigando estos concejos contra el conde de Aguilar, su señor, y aunque el proceso se demoró durante muchos años, finalmente consiguieron que se sentenciase a su favor, obligando a éste a poner fin a la exigencia de una serie de prestaciones injustificadas.

Durante el prolongado período de tiempo que duró el litigio el conde, sin embargo, no ahorró en medios para amedrentar a sus vasallos, a fin de que desistiesen de llevar adelante la demanda judicial contra él iniciada. Fueron muchos, en efecto, los vecinos de las Cinco Villas y Valdecanales que entonces se vieron obligados a huir de sus casas, por temor a ser atacados por el conde o sus criados. Así nos lo confirma en primer lugar la comisión dada en 1493 por los reyes al licenciado Francisco de Tapia, corregidor de Soria, para que se trasladase a estos lugares e hiciese regresar a sus casas a todos los vecinos que estuviesen huidos o desterrados por el conde «a cabsa de querer demandar e seguir la livertad de las dichas villas», garantizándoles la devolución de los bienes que éste les hubiese tomado ${ }^{20}$. Este comisionado regio debió alcanzar, no obstante, un éxito muy limitado en su empresa, puesto que tres años después, en 1496, los reyes comisionaron de nuevo a un contino de su Corte, Juan Flores, para que impartiese justicia a ciertos vecinos de estos mismos lugares que, a pesar de encontrarse amparados por una carta de seguro real, andaban huidos de sus casas, temerosos del conde de Aguilar y sus criados, y para que les restituyese las prendas que éste les había tomado ${ }^{21}$.

Todas las presiones ejercidas por el conde no bastaron para que sus vasallos renunciaran a su objetivo de alcanzar justicia, y finalmente en el año 1500 obtuvieron una victoria importante, al ser expedida en su favor una carta ejecutoria, en la que se recogían muchas de sus aspiraciones. El conflicto no acabó, sin embargo, aquí. Desconocemos cuál fue la reacción inmediata del conde cuando fue requerido con la carta ejecutoria para que la cumpliese. Pero sí nos consta que, aprovechando la situación de inestabilidad que se abrió en Castilla tras la muerte de la reina Isabel la Católica en noviembre de 1504, volvió a redoblar sus presiones sobre sus vasallos para que lo que éstos habían conseguido con grandes es-

${ }^{20}$ La provisión dirigida al corregidor de Soria, fechada en Barcelona 24-I-1493, está inserta en AchV(=Archivo de la Chancillería de Valladolid), RE (=Registro de Ejecutorias), C. 148 (VII-1500).

${ }^{21}$ AGS (=Archivo General de Simancas), RGS (=Registro General del Sello), X-1496, fol. 171, y XI-1496, fol. 69. 
fuerzos por la vía judicial quedase reducido a letra muerta. Así nos lo testimonia, por ejemplo, un documento otorgado por el concejo de Mansilla el 28 de julio de 1505 , en el cual los vecinos de este lugar denunciaron que por parte del conde de Aguilar, sus alcaldes mayores, y Don Juan de Arellano, su primo:

«nos han sido puestos grandes temores y miedos, diciendo que por el pleito que con su señoría tratamos y por la sentencia que fue dada por sus altezas en el Consejo contra el conde, que nos han de matar, destruir y asolar, y que después que la reina doña Isabel nuestra señora es muerta no nos ha de valer la sentencia, y que no hay rey en Castilla, y que si la dicha sentencia no rasgamos que somos perdidos, y con otros muchos temores que el conde nuestro señor nos ha puesto, y mucho más don Juan de Arellano, su primo, nos han puesto, prendiendo hombres, dándoles tormentos y azotes, en especial a los que siguieron más el dicho pleito, tomándoles sus haciendas y bienes y ganados, segándoles los panes, y sacando de las iglesias a los que se acogían a ellas, todo por los atraer a que hiciesen ciertos compromisos, todo en perjuicio de las sentencias y cartas ejecutorias, y para poner nuevos tributos sobre la villa»22.

Para entonces la monarquía ya había expedido una carta de seguro en favor de los vecinos de las Cinco Villas y Valdecanales, para protegerlos de las posibles agresiones de su señor, fechada en abril de 1505 , que volvería a ser reiterada, a petición de los propios vecinos, al año siguiente, en el mes de julio ${ }^{23}$. Y además fue enviado un juez pesquisidor, el licenciado Francisco Pérez de Vargas, para que hiciese derramar la gente que se había juntado en ciertas asonadas que habían tenido lugar como consecuencia de las diferencias planteadas entre el conde de Aguilar y sus vasallos de las Cinco Villas y Valdecanales, y castigase a las personas culpables de que tales «ayuntamientos de gentes», prohibidos por las leyes del reino, hubiesen tenido lugar ${ }^{24}$.

No hay duda, por tanto, de que el conde había decidido recurrir al uso de la fuerza para imponer sus criterios a sus vasallos, haciendo caso omiso de las disposiciones de los tribunales de justicia de la monarquía. Y en este contexto habría que explicar los «ayuntamientos de gentes» aludidos en las cartas de comisión al pesquisidor Vargas, que tendrían como principal objetivo el de intimidar, aunque tampoco hay que excluir que en ocasiones derivasen en incontroladas acciones violentas. La actitud del conde de Aguilar era en cualquier caso de claro desafío a la autoridad monárquica, y en cierta medida se explica como consecuencia de la confusión que en aquellos momentos reinaba en torno a la identidad de la persona que la encarnaba, habida cuenta que la legítima reina, doña Juana, se encontraba todavía fuera de Castilla, y existían serias dudas sobre su capacidad de hacerse cargo de las riendas del gobierno del reino. Con todo las instituciones seguían en

22 AGS, Cámara-Pueblos, leg. 11, Mansilla, 28-VII-1505.

${ }^{23}$ Las dos cartas de seguro en AGS, RGS, IV-1505 y VII-1506.

${ }_{24}$ AGS, RGS, X-1505, fol. 246. Prórroga de la comisión dada al licenciado Francisco Pérez de Vargas, pesquisidor. 
pie, y en rigor sus decisiones habían de ser respetadas. Pero las actuaciones del conde de Aguilar, como las de otros muchos nobles castellanos en aquellos críticos años, demuestran que todavía el normal funcionamiento del aparato institucional de la monarquía continuaba dependiendo de la capacidad de liderazgo del monarca reinante, y que en ausencia de uno capaz de hacer respetar su autoridad no faltaban nobles prestos a ocupar su lugar en aquellos ámbitos regionales donde disponían de sólidas bases para el ejercicio del poder.

En los años que siguieron a la muerte de la reina Isabel las instituciones de gobierno central de la monarquía estuvieron enviando uno tras otro jueces pesquisidores a las Cinco Villas y Valdecanales para responder a las demandas de justicia presentadas por sus vecinos, que solicitaban protección frente a su señor, pero todos tropezaron con insalvables dificultades para cumplir su misión, incapaces de imponerse por la fuerza al conde de Aguilar. Así, al ya referido licenciado Francisco Pérez de Vargas le sucedió meses después el bachiller Alderete, quien recibió comisión del rey Felipe el Hermoso para tomar información sobre los abusos que estaba cometiendo el conde contra sus vasallos. A los pocos días se produjo, sin embargo, la imprevista muerte del rey, y el vacío de poder creado fue de nuevo aprovechado por el conde para desafiar la autoridad de la monarquía, dado que se atrevió incluso a perseguir a este pesquisidor con amenazas de prenderle y matarle. Nada pudo hacer, por tanto, para desagraviar a los vecinos de las Cinco Villas y Valdecanales, pero, a pesar de todo, éstos no perdieron las esperanzas, y tiempo después recurrieron de nuevo al Consejo Real en demanda de justicia. En respuesta consiguieron que se nombrase un nuevo juez pesquisidor, el alcalde Gallegos, quien para cumplir con su delicada misión acudió reforzado con una pequeña compañía de hombres de armas, con la que se instaló en el lugar de Barbadillo. Pero de nuevo en esta ocasión el conde adoptó una actitud desafiante, ya que, antes de que el pesquisidor pudiera entrar en sus señoríos, procedió a juntar gente armada para combatirle, llegando a reunir, según una versión sin duda exagerada, más de 6.000 hombres, entre los que también había al parecer seguidores del Condestable. Y ante tamaña demostración de fuerza el alcalde Gallegos no se atrevió a entrar en las Cinco Villas y Valdecanales, dejando sin cumplir la misión para la que había sido designado 25 .

Ante estas reiteradas muestras de desobediencia, la monarquía no permaneció impasible sino que trató de adoptar medidas drásticas para hacer respetar su autoridad, pero al parecer siempre con un éxito limitado. Así, por ejemplo, nos consta que tras los jueces pesquisidores mencionados fue enviado hacia 1510 uno nuevo, el licenciado Villafañe, alcalde de Casa y Corte, que dictó sentencias de destierro contra el conde de Aguilar y su esposa, obligando al

${ }^{25}$ Las informaciones sobre las misiones del bachiller Alderete y del alcalde Gallegos las tomamos de la relación incluida en la comisión al licenciado Juan Fernández de Pinilla. AGS, RGS, II-1523. 
primero a residir en un radio de cinco leguas en torno a la Corte, so pena de 20.000 castellanos, y a la segunda a marchar fuera de la villa de Yanguas para fijar su residencia en la de Cervera. Pero tampoco en esta ocasión los condes se apresuraron a cumplir lo ordenado por el delegado regio, sino que optaron por recurrir a tácticas dilatorias, enviando a un representante a la Corte para informar que de buena gana cumplirían lo que se les había ordenado, si no fuese porque el conde se encontraba muy enfermo «de pasión del corazón» y de «gota artetica» y de otras enfermedades, mientras que la condesa estaba «recién parida, y se le habían recrecido calenturas». De modo que al rey no le quedó otra opción que enviar a Yanguas un nuevo delegado, en esta ocasión el bachiller Fernán Álvarez Albarca, para que comprobase in situ cuál era el verdadero estado de salud de los condes $^{26}$.

No hemos encontrado más noticias sobre el envío de nuevos jueces pesquisidores en los años siguientes, en los que aparentemente la tensión fue disminuyendo en las relaciones de los condes de Aguilar con sus vasallos de las Cinco Villas y Valdecanales. Y desde esta perspectiva resulta muy sintomático el hecho de que estos últimos, por lo que sabemos, no aprovecharon las circunstancias excepcionales del año 1520 para levantarse contra su señor el conde, siguiendo el ejemplo de las cercanas ciudades de Nájera y $\mathrm{Haro}^{27}$. No podemos entrar aquí a tratar de determinar las razones por las que no lo hicieron, pero en cualquier caso sí conviene dejar claro que no pudo ser porque considerasen ya plenamente superadas sus diferencias con sus señores, puesto que pocos meses después de haber quedado plenamente sofocada la rebelión comunera, hacia febrero de 1523, los representantes de estas villas recurrieron de nuevo ante la monarquía en demanda de justicia, denunciando los numerosos agravios recibidos de los sucesivos condes desde hacía varias décadas, pero muy en especial tras la muerte de la reina Isabel la Católica. Y por enésima vez se decidió enviar para desagraviarles a un juez pesquisidor, el licenciado Juan Fernández de Pinilla, quien cabe presumir que alcanzase mayor éxito que sus predecesores en su empresa, aunque esto es algo que no hemos podido entrar a comprobar ${ }^{28}$. Pero al margen de cuál fuera el resultado de su actuación, lo que nos interesa aquí recalcar es que más de veinte años después de que los concejos de las Cinco Villas y Valdecanales hubiesen obtenido una importante victoria frente a sus señores en sede judicial, sus vecinos continuaban sometidos a una insoportable presión señorial, que había impedido la ejecución de lo dispuesto en las sentencias pronunciadas por los tribunales de la monarquía. Y esta constatación nos confirma hasta qué punto fue limitado el éxito alcanzado por los Reyes Católicos en su empresa de someter al control de la monarquía la acción de gobierno

\footnotetext{
${ }^{26}$ AGS, RGS, X-1510. Comisión al bachiller Fernán Álvarez Albarca.

27 Vid. MALDONADO, Ramón José: «La Rioja en la Guerra de las Comunidades», Berceo, 3 (1948), pp. 383-391.

${ }_{28}$ AGS, RGS, II-1523. Comisión al licenciado Juan Fernández de Pinilla
} 
de los miembros de la alta nobleza en sus propios señoríos, al menos en la región riojana.

Lo ocurrido en las Cinco Villas y Valdecanales no tuvo, por otra parte, carácter excepcional, aunque sí es cierto que estos lugares destacaron por ser los más conflictivos en toda la Rioja durante este período. No obstante episodios puntuales de abusos contra sus propios vasallos protagonizados por miembros de la alta nobleza los hubo en un número relativamente importante en esta región, como testimonian, por ejemplo, las cartas de seguro expedidas por los reyes en favor de algunos de dichos vasallos ${ }^{29}$. Pero especialmente duros se mostraron los miembros de la alta nobleza riojana contra aquellos de sus vasallos que pasaron a ponerse al servicio de otro noble con el que rivalizaban por alcanzar la hegemonía en la región.

Un testimonio interesante en este sentido nos lo proporciona lo ocurrido en las villas de Navarrete, del señorío del duque de Nájera, y la vecina Entrena, del señorío del conde de Aguilar, en los años 1513 y 1514 . El origen del problema estuvo en que, habiendo ordenado castigar el duque de Nájera a algunos vecinos de Navarrete que llevaban de él acostamiento, por no haber acudido a la guerra de conquista de Navarra, como estaban obligados, éstos reaccionaron pasándose a vivir a la cercana villa de Entrena. Encolerizado por este acto de deslealtad el duque ordenó que se les embargasen todos los bienes que poseyesen en el término de Navarrete y se echasen huéspedes en sus casas, llegando incluso a decretar la pena de muerte sobre sus personas. Y, no contento con esto, también tomó medidas contra los vecinos de la villa de Entrena, vasallos de su rival el conde de Aguilar, que les habían acogido, ordenando en primer lugar que se pusiesen guardas en las puertas de Navarrete que impidiesen la entrada a los vecinos de Entrena, vasallos del conde de Aguilar, que poseían allí casas y bodegas con vino, y en segundo lugar que se prohibiese a todos sus vasallos vecinos de Navarrete, Medrano y Fuenmayor, que mantuviesen cualquier tipo de conversación con vasallos del conde, muy en particular con los que fuesen vecinos de Entrena ${ }^{30}$. Se trataba, por tanto, de medidas que iban en contra de lo dispuesto por la legislación general del reino, que garantizaba la libre circulación de las personas, y por ello fueron denunciadas antes las instituciones centrales de gobierno de la monarquía. Pero, como siempre, la capacidad de éstas para lograr su erradicación demostró ser bastante limitada. Y así lo pudieron experimentar en sus propias carnes algunos individuos en particular que, habiendo despertado las iras de sus señores, fueron sometidos a malos tra-

29 A título ilustrativo sirvan los siguientes ejemplos. AGS, RGS, VIII 1496, fol. 164. Seguro para Juan Ruiz, vecino de San Román de Cameros, que se temía de Carlos de Arellano, y de su padre, el conde de Aguilar. AGS, RGS, VII-1512. Seguro para Diego Martínez, vecino de San Román, y su nieta, que se temían de Carlos de Arellano, conde de Aguilar. AGS, RGS, I-1518. Seguro para Alonso Moreno, vecino de Nájera, que se temía del duque de Nájera. AGS, RGS, VIII-1499, fol. 114. Seguro para unos vecinos de Navajún, que se temían del conde de Aguilar, Carlos de Arellano.

${ }^{30}$ Nos basamos en varias provisiones de AGS, RGS, I-1514, II-1514 y VIII-1514. 
tos durante prolongados períodos de tiempo, como le ocurrió a Hernán Martínez de Navarrete, tesorero del duque de Nájera, quien, siendo ya de avanzada edad, fue mantenido preso en muy duras condiciones por su señor en una torre del alcázar de Nájera, al parecer por razón de haber casado un hijo suyo con una hija del alcaide de Nalda, oficial del conde de Aguilar ${ }^{31}$.

\section{LOS PEQUEÑOS SEÑORÍOS NOBILIARIOS EN LA ÓRBITA DE LOS GRANDES LINAJES}

El potencial político y militar de los miembros de la alta nobleza en el período que estamos analizando estaba determinado en gran medida por su capacidad de movilización de hombres armados, y de ahí que se mostrasen tan implacables ante los casos de «deserción» protagonizados por aquellos de sus vasallos que buscaban el establecimiento de contactos con sus rivales, o entraban directamente a su servicio, abandonando la fidelidad a ellos debida como señores. En principio era en sus propios señoríos donde estos miembros de la alta nobleza podían con más facilidad reclutar hombres de armas, pero no les bastaban para sustentar sobre unas bases suficientemente sólidas su posición de poder en el ámbito regional frente a otras casas nobles rivales, y por ello debían recurrir a otros procedimientos para engrosar sus clientelas.

Desde este punto de vista les ofrecían un importante potencial los numerosos señoríos en manos de miembros de la pequeña nobleza que a fines de la Edad Media había desperdigados por todo el territorio riojano. Y, en efecto, nos consta que los representantes de la alta nobleza prodigaron esfuerzos por integrar en sus clientelas a los titulares de dichos señoríos, cuando no recurrieron a otros procedimientos más irregulares para colocarlos bajo su órbita de influencia, sin descartar el uso de la fuerza bruta. Pero también conviene tener en cuenta que en ocasiones excepcionales los propios miembros de la alta nobleza se desprendieron de algunos de sus señoríos para premiar con ellos los servicios prestados por algún destacado caballero de sus clientelas, aunque lo cierto es que esta práctica fue muy inhabitual, de modo que el único caso relevante que tenemos bien documentado es el de la cesión por vida efectuada por Juan Ramírez de Arellano a Diego López de Medrano del lugar de Cocera ${ }^{32}$, pues la donación de la villa de Jubera por los Manrique a Diego Fernández de Lezana no es un hecho suficientemente probado ${ }^{33}$.

31 Vid. Montero Tejada, Rosa María: Nobleza y sociedad en Castilla..., p. 148.

32 A pesar de haberlo recibido en merced de por vida, Diego López de Medrano lo transmitió en herencia a su hijo Pedro de Medrano, quien luego a su vez lo cedió al concejo de Nieva de Cameros. El primer conde de Aguilar, hijo del primer conde de Arellano, tras pleitear en la Chancillería de Valladolid consiguió que se obligase al concejo de Nieva a restituirle dicho lugar. Vid. AChV, RE, C. 2, III-1486.

${ }_{33}$ El primer duque de Nájera en su testamento se limitó a hacer constar que «Jubera siempre oí decir que había sido de mi casa y que uno de mi linaje la dio a un caballero que llaman Diego 
Todavía no se dispone de ningún estudio monográfico que permita conocer en detalle la evolución del mapa señorial riojano durante el período medieval, por lo que son muchas las incógnitas que persisten sobre el momento de constitución de los distintos señoríos y la identidad de sus sucesivos titulares. No es nuestra intención entrar aquí a tratar de colmar este vacío epistemológico, y por tanto nos limitaremos a hacer unos breves comentarios de carácter general sobre las peculiaridades de los pequeños señoríos, y sobre la identidad de sus titulares. Así, en primer lugar, interesa destacar el hecho de que éstos proporcionaron una importante plataforma para el arraigo en la región riojana de una pequeña nobleza rural que por el contrario está totalmente ausente, o muy poco desarrollada, en otras regiones de la Corona de Castilla donde los titulares de los pequeños señoríos eran en su práctica totalidad miembros de las oligarquías urbanas.

En efecto, el hecho de que las ciudades realengas riojanas a fines de la Edad Media todavía continuaban estando gobernadas por oficiales que ejercían mandatos de carácter anual, y se renovaban todos los años, entre los cuales por otra parte a veces dominaban en número los pecheros frente a los hidalgos, no favoreció que las familias nobles titulares de señoríos mostrasen interés por integrarse en esas sociedades políticas urbanas. Para dichas familias el ejercicio de un oficio de gobierno urbano de estas características debía representar más bien un demérito desde el punto de vista de la preservación de su rango, y de ahí que nunca encontremos a miembros de las mismas desempeñándolos. Pero, además, por otra parte, como veremos, los propios órganos concejiles de las principales ciudades realengas de la Rioja mostraron una fuerte resistencia a admitir que caballeros señores de vasallos llegasen siquiera a residir temporalmente en ellas, llegando a prohibirles de forma expresa la adquisición de casas en el interior de los recintos urbanos.

Por éstas y otras razones la pequeña nobleza titular de señoríos de vasallos mantenía en la Rioja a fines de la Edad Media un carácter esencialmente rural, lo que no impedía que algunas familias en particular fuesen propietarias de capillas funerarias ubicadas en iglesias o monasterios de los principales núcleos urbanos de la región. Pero también conviene tener en cuenta que los múltiples avatares por los que atravesaron estos pequeños señoríos a veces propiciaron que terminasen en manos de titulares absentistas, que no respondían al perfil característico de la pequeña nobleza rural. Y a título de simple ejemplo ilustrativo recordaremos el caso de los Franco, señores de Préjano, que eran descendientes de judíos toledanos y tenían fijada su residencia desde mediados del siglo XV en Valladolid, donde desempeñaron destacados oficios de gobierno, como el de regidor ${ }^{34}$.

Fernández de Lezana a condición que si muriese sin hijos torne a mi casa». Copia del testamento en RAH (= Real Academia de la Historia), Salazar y Castro, M-1, fols. 92-6.

${ }^{34}$ Información de carácter genealógico sobre esta familia de judeoconversos toledanos en 
La mayor parte de los pequeños señoríos existentes en la Rioja a fines del siglo XV y comienzos del siglo XVI contaban entonces, no obstante, con señores residentes, que eran caballeros desvinculados en gran medida de los principales núcleos urbanos de la región, y sólo podían aspirar a vivir a la sombra de los representantes de los linajes de alta nobleza, que en todo momento estuvieron interesados por atraerlos hacia su órbita de influencia. De hecho las rivalidades desatadas entre estos linajes crearon unas condiciones favorables para los caballeros de la pequeña nobleza rural a la hora de negociar su entrada al servicio de los primeros, pues incrementaron su capacidad de presión al reservarles la baza de la amenaza de pasarse al servicio del rival, que por lo demás en más de una ocasión fue llevada a la práctica, como podremos comprobar.

Antes de pasar a analizar la problemática planteada por la competencia desatada entre los linajes de alta nobleza riojana por integrar en sus clientelas a los principales representantes de la pequeña nobleza rural de la región, muy en particular a los que eran señores de vasallos, conviene detenerse, no obstante, brevemente en dar cuenta de su identidad. Para empezar tenemos que un importante número de ellos eran miembros de ramas cadetes de esos mismos linajes que rivalizaban por la hegemonía en la región, sobre todo de los Arellano ${ }^{35}$ y de los Manrique ${ }^{36}$. Las relaciones que éstos mantuvieron con sus parientes mayores fueron muy complejas, pues aunque habitualmente colaboraron en numerosas empresas, no estuvieron ausentes tampoco los episodios de frontal enfrentamiento, que propiciaron que la monarquía tuviese que expedir cartas de seguro en favor de segundones de estos linajes amenazados por sus parientes mayores $^{37}$. Y que los temores que llevaban a solicitar estas cartas de seguro no estaban injustificados lo prueban en más de una ocasión las actuaciones de los nobles más poderosos, que no dudaron en agredir a sus parientes más débiles para incrementar su propio poderío personal. Es lo que hizo, por ejemplo, en 1503 el conde de Aguilar, quien a raíz de producirse la muerte de su pariente Juan Enríquez de Arellano, señor de Munilla, que había dejado como sucesor a un hijo ilegítimo llamado Francisco de Arellano, al cual habían legitimado los reyes, entró por la fuerza con gente armada de a pie y de a caballo en esta villa

MolÉnAt, Jean Pierre: Campagnes et monts de Tolède du XIIe. Au XVe. siècle, Madrid, 1997, pp. 576 y ss. RAH, Colección Salazar y Castro, D-25, fol. 205v. Y COOPER, Edward: Castillos señoriales en la Corona de Castilla, Valladolid, Junta de Castilla y León, 1991, vol. I, p. 465.

35 Información detallada sobre miembros de ramas cadetes del linaje Arellano que fueron titulares de señoríos de vasallos en Rioja en DiAGO HERNANDO, Máximo:»Implantación territorial del linaje Arellano...». También aporta noticias Moreno Ramírez De Arellano, Miguel Ángel: Señorío de Cameros y condado de Aguilar...

${ }^{36}$ Información, aunque no de carácter exhaustivo, sobre los señoríos que poseyeron las ramas cadete de los Manrique en la Rioja en Montero TejadA, Rosa: Nobleza y sociedad en Castilla... Se ha de destacar por su importancia a la rama que fue titular del señorío de Valdezcaray.

37 Vid. por ejemplo AGS, RGS, I-1496, fol. 57. Carta de seguro para Alfonso de Arellano, señor de la villa de Clavijo, que se temía de su hermano el conde de Aguilar. Y XII-1506. Seguro a Fadrique de Arellano, que se temía de los condes de Aguilar. 
serrana, y nada más haber concluido el entierro del difunto señor tomó por la fuerza a Francisco de Arellano y lo llevó preso a su fortaleza de Yanguas ${ }^{38}$.

Un segundo grupo de señores de vasallos estaba constituido por miembros de linajes que o bien habían tenido un notable protagonismo en la historia de Castilla en otros momentos del pasado o bien lo continuaban teniendo en sus ramas principales, que habían terminado arraigando fuera de la Rioja, mientras que en esta región sólo quedaban representantes de ramas secundarias con escasos medios económicos y prácticamente nula influencia.

Entre los linajes de pasado glorioso se ha de destacar el de los Leiva, titulares de varios señoríos en la Rioja Alta, en el entorno de Santo Domingo de la Calzada, descendientes de Juan Martínez de Leiva, que en su momento había destacado por ser uno de los principales hombres de confianza del rey Alfonso XI, junto con Garcilaso de la Vega y Alvar Núñez Osorio. El principal representante de este linaje a fines del siglo XV y comienzos del siglo XVI era Juan de Leiva, un individuo identificado en las fuentes como vasallo del rey, que era señor, entre otros, de los lugares de Tobía, que adquirió por compra a los condes de Nieva39, Leiva ${ }^{40}$ y Baños de Rioja ${ }^{41}$. Fue un individuo al parecer bien relacionado en la Corte, pues nos consta que, al menos, ejerció el oficio de corregidor en la ciudad de Cáceres ${ }^{42}$. Pero en el ámbito regional riojano, aunque ciertamente despertó los recelos de la ciudad de Santo Domingo de la Calzada, con la que tuvo varios enfrentamientos por problemas de jurisdicción, y que ofreció una feroz resistencia a admitir que fijase en ella su residencia, ocupó una posición de segunda fila en la escena política, como bien lo demuestra el hecho de que formaba parte de la clientela del duque de Nájera. ${ }^{43}$.

También de clara segunda fila era la posición a la que habían quedado relegados los representantes del linaje Estúñiga que permanecían arraigados en el territorio riojano a fines de la Edad Media, que sólo controlaban señoríos de importancia menor, que en ocasiones incluso se vieron obligados a vender para hacer frente a sus dificultades financieras. Es el caso de los sucesores en el mayorazgo fundado por el obispo de Calahorra Don Diego de Estúñiga, que en el transcurso de la segunda mitad del siglo XV experimentaron una acelerada

38 AGS, RGS, X-1503.

39 AGS, RGS, XII-1500, fol. 5. Licencia a los condes de Nieva para vender la villa de Tobía a Juan de Leiva.

40 AGS, RGS, VI 1510. Juan de Leyva tiene privilegio para que sus lugares de Leyva y Tobía no paguen en los servicios, pero ahora se les quiere hacer pagar con los otros vecinos de la Tierra de Rioja.

41 AGS, RGS, IX-1510. La ciudad de Santo Domingo de la Calzada había denunciado que, perteneciéndole a ella la jurisdicción criminal de Baños de Rioja, Juan de Leiva había puesto allí una picota.

42 AGS, RGS, IV 1510. Prórroga del corregimiento de Cáceres a Juan de Leiva.

43 Entre las razones alegadas por Santo Domingo de la Calzada para negarse a admitir que Juan de Leiva pudiese comprar casas en la ciudad y fijar su residencia en ella figuró la de que vivía con el duque de Nájera. Vid. AGS, RGS, X-1507. Ejecutoria a petición de Juan de Leiva contra la ciudad de Santo Domingo. 
pérdida de influencia política, agravada por importantes dificultades financieras que les obligaron a vender muchos de sus señoríos, tales como Torre, Luezas y Ribabellosa, adquiridos por el conde de Aguilar, y Castroviejo, comprado por Juan de Leiva ${ }^{44}$. A fines de este siglo el único señorío importante que conservaban era el del valle de Las Cuevas, que incluía las villas de Castañares, Pabía, Navajas y San Provencio. Pero a duras penas consiguieron mantener allí una posición independiente, puesto que, entre otras cosas, se lo impidió la amenazante vecindad del conde de Aguilar, señor de la cercana villa de Vigue$\mathrm{ra}$, con la que mantuvieron relaciones sumamente tensas, que en algunas ocasiones derivaron en graves actos de violencia, como los denunciados por Diego Arista de Zúñiga en $1509^{45}$.

De hecho los enfrentamientos entre los Estúñiga de Las Cuevas y los condes de Aguilar se prolongaron durante varias décadas, y en algunos momentos alcanzaron cotas de extrema gravedad, como ocurrió hacia 1485, cuando Juan Arista de Zúñiga fue despojado violentamente de la posesión de la fortaleza de Las Cuevas por gentes de la Hermandad, al parecer procedentes en su mayoría de la Tierra del conde de Aguilar ${ }^{46}$. Las informaciones que proporciona la documentación sobre este episodio resultan bastante confusas, puesto que por un lado en algunos documentos se pone el acento en presentar a Juan Arista de Zúñiga, hijo de Diego Arista de Zúñiga, como un bandolero que cometía con frecuencia robos y hurtos de ganados desde la fortaleza de Las Cuevas, donde residía, y se justifica la intervención de la Hermandad para tomar por la fuerza esta fortaleza como justa represalia por la quema realizada por Juan Arista de Zúñiga en el campo de veinticinco cuchares de unos vasallos del conde de Aguilar, y por la paliza que este caballero había dado a un cuadrillero de la Hermandad $^{47}$. Pero, por otro lado, el propio Diego Arista de Zúñiga, padre de Juan, tras denunciar al duque de Nájera y al conde de Aguilar por haberse apoderado a la fuerza de su villa y fortaleza de Las Cuevas, solicitó a la monarquía carta de seguro que le amparase de nuevas agresiones de estos poderosos nobles contra su persona y patrimonio ${ }^{48}$.

\footnotetext{
${ }_{44}$ Referencias al respecto en Diago Hernando, Máximo: «Linajes navarros en la vida política de la Rioja...», p. 574.

45 AGS, RGS, VII-1509. Provisión al corregidor de Santo Domingo de la Calzada. Diego Arista de Zúñiga, señor del valle de Las Cuevas, había denunciado que algunos vecinos de Viguera, vasallos del conde de Aguilar, desde hacía unos quince años habían entrado a romper y labrar parte de los términos de sus villas, y los tenían ocupados por la fuerza. Además, hacía poco tiempo habían entrado "armados en son de escándalo y alboroto", segando el cereal que estaba sembrado, y llevándose consigo lo cosechado a Viguera. Y, por fin, se habían atrevido incluso a derribar la horca de la villa de Castañares.

${ }^{46}$ Información detallada sobre este episodio y sus posteriores secuelas en AGS, CámaraPueblos, leg. 7, Logroño, 29-X-1493.

47 Ibid.

48 AGS, RGS, XI-1487, fol. 31. Seguro a favor de Diego Arista de Zúñiga, señor de la villa y fortaleza de Las Cuevas, defendiéndole del duque de Nájera y del conde de Aguilar, que se habían
} 
En qué medida los Estúñiga de Las Cuevas eran a finales del siglo XV unos agresivos bandoleros o víctimas del afán expansionista de los miembros de la alta nobleza de su entorno es algo que no podemos entrar aquí a dilucidar. Pero de lo que no cabe duda es de que habían descendido a la posición de unos empobrecidos hidalgos rurales, que por las razones que fuese no habían entrado en la órbita de influencia de alguno de los grandes linajes nobles de la región, y quizás por ello se vieron abocados a mantener unas relaciones más conflictivas con sus vecinos.

Otro linaje de alta nobleza que estaba representado en tierras riojanas a fines de la Edad Media por una empobrecida rama secundaria era el de los Luna, originario de Aragón, y que había alcanzado grandes cotas de poder en Castilla en tiempos del Condestable Don Álvaro. En concreto a miembros de este linaje pertenecían en señorío las villas de Cornago y Jubera, que habían tenido una azarosa trayectoria a lo largo del siglo XV, y durante el reinado de los Reyes Católicos escaparon en gran medida a su control efectivo, bien por serles disputado el título de su propiedad, o bien por haber cedido ellos en prenda alguno de estos lugares a cambio de recibir en préstamo importantes cantidades de dinero. En concreto fue el duque de Nájera el que disputó la titularidad del señorío de Jubera a los Luna, alegando que esta villa había sido concedida en señorío por Enrique II a Pedro Manrique, el viejo ${ }^{49}$. Y por su parte el conde de Aguilar en 1493 prestó a Juan de Luna la cantidad de $300.000 \mathrm{mrs}$. que éste necesitaba imperiosamente para hacer frente a los gastos generados por los pleitos que entonces estaba siguiendo, a cambio de recibir en concepto de prenda hipotecaria la propia villa de Jubera, que mantendría bajo su control hasta haber recuperado la cantidad prestada ${ }^{50}$. Pero ya muchos años antes de que tuviese lugar esta transacción los condes de Aguilar habían comenzado a intervenir en los asuntos internos de los señoríos riojanos de los Luna, como se desprende de una provisión del año 1480 por la que se requería al conde de Aguilar que devolviese a María de Luna lo que le tenía ocupado en Jubera y le pertenecía por su dote ${ }^{51}$. Y por otra parte un documento del año 1500 nos informa que desde hacía 30 años los condes de Aguilar habían tenido en encomienda ciertas aldeas de la villa de Jubera, que por este motivo estaban apartadas de las restantes, y celebraban concejo apartado, poniendo alcaldes por su parte. Y esta circunstancia había dado lugar a un grave altercado en un día de mayo de 1499, cuando Alonso de Zúñiga, un hombre del duque de Nájera, quien entonces tenía la villa de Jubera, fue junto con otros hombres armados al término de Censano, una de las aldeas en encomienda del conde, y tomó presos al alcalde, merino y cura, llevándolos consigo al cepo a la villa de Jubera ${ }^{52}$.

apoderado de su casa y fortaleza. Y I-1488, fol. 265. Seguro a favor de Diego Arista de Zúñiga, que se recelaba del duque de Nájera.

${ }_{49} \mathrm{RAH}$, Salazar y Castro, M-140. fols. 336-46. Relación sumaria del pleito que el duque de Nájera trata contra Álvaro de Luna.

50 Archivo Histórico Nacional, Osuna, leg. 3364-13, Yanguas, 12-IX-1493.

${ }^{51}$ AGS, RGS, VI-1480, fol. 182.

52 AGS, RGS, IX-1500. 
Pasando a otro capítulo, también había en la Rioja a fines de la Edad Media señores de vasallos que pertenecían a linajes de rango medio, sobre los que con frecuencia es poco lo que se sabe con certeza por falta de estudios monográficos dedicados a la reconstrucción de sus trayectorias. Sin ánimo de ofrecer una relación exhaustiva de los mismos cabe mencionar en primer lugar a los Medrano, de origen navarro, pero que se instalaron tempranamente en la Rioja, donde poseyeron los señoríos de Agoncillo, Almarza de Cameros, Fuenmayor y la torre de Islallana. En Agoncillo les sucedieron por matrimonio los Porras, originarios de la montaña burgalesa, que durante muchos años controlaron también la tenencia de la fortaleza de Los Arcos, y adquirieron además por compra el señorío de Huércanos. Por su parte los Puelles poseyeron el señorío de la villa de Autol, en la Rioja Baja, y tuvieron bajo su control en determinados momentos la villa de Anguciana, en la Rioja Alta, que formaba parte del mayorazgo de una rama del prolífico linaje de los Salcedos3. La villa de Quel fue propiedad durante la segunda mitad del siglo XV de los García de Alfaro, tras haberla comprado hacia 1455 García Sánchez de Alfaro, el Viejo, a Leonor Téllez ${ }^{54}$. En este mismo ámbito se localizaba la villa de Robres, de la que fueron señores miembros del linaje Lezana. Y, por fin, en el ámbito de la Rioja Alta hay que destacar al linaje de los Londoño, que había medrado a la sombra del infante Juan, rey de Navarra, y a fines del siglo XV mantenía en su poder, entre otros, los señoríos de Hervías, Hormilla y Hormilleja.

Los miembros de todos estos linajes, que con frecuencia estaban entrelazados por múltiples vínculos matrimoniales, no disponían en la época que estamos analizando de medios suficientes para mantener una posición independiente en un territorio marcado por una encarnizada rivalidad entre los linajes de alta nobleza por alcanzar la hegemonía política en la región. Sus señoríos eran demasiado pequeños, y además ni siquiera en todos los casos se había tomado la precaución de incorporarlos a mayorazgos, por lo cual a veces debieron ser objeto de partición entre varios herederos, y esta práctica terminó por aniquilar su ya de por sí escaso potencial político.

Un ejemplo paradigmático en este sentido nos lo proporciona el señorío de Quel, villa que por virtud de los repartos sucesorios llegó a tener simultáneamente en los primeros años del siglo XVI nada menos que cinco señores, hecho que generó una gran inestabilidad que, además de contribuir al deterioro de las

53 Vid. AGS, RGS, X-1480, fol. 75. Receptoría en el pleito entre Íñigo López de Salcedo y Alfonso de Puelles, sobre la posesión del lugar de Anguciana, que, según el primero, era de su mayorazgo, y le había sido arrebatada por el segundo durante su minoría de edad. En 1476 se había ordenado, no obstante, a los alcaldes de la merindad de Rioja que amparasen a Alonso de Puelles, señor de Anguciana, en la posesión de este lugar. AGS, RGS, XI-1476, fol. 760.

${ }^{54}$ Este año el conde de Haro, Pedro Fernández de Velasco, autorizó a García Sánchez de Alfaro a poder comprar el lugar de Quel. Vid. DE la PeÑa MaraZuela, Ma.Teresa, y LeÓn Tello, Pilar: Archivo de los Duques de Frías. I. Casa de Velasco, Madrid, 1955, p. 381, nº 2307. 
relaciones de dichos señores con sus vasallos ${ }^{55}$, y de provocar graves desórdenes de orden público ${ }^{56}$, brindó una magnífica oportunidad a los miembros de la alta nobleza con intereses en la comarca para colocar bajo su órbita de influencia este estratégico lugar. Y, en efecto, nos consta, que su fortaleza terminó quedando bajo control conjunto de los condes de Aguilar y de Nieva, aunque de momento no hemos podido determinar los motivos concretos por los que se produjo este extraño fenómeno. Sólo sabemos que en 1518 la viuda de un tal Juan Fernández informó a los reyes que dos partes de la fortaleza de Quel pertenecían al difunto conde de Aguilar y a su viuda la condesa, y la tercera parte restante al conde de Nieva, y que hacía unos seis años los condes de Aguilar habían entregado la tenencia de dicha fortaleza a su difunto marido, acordando entregarle cada año en concepto de salario $2.600 \mathrm{mrs}$., 10 fanegas de trigo y 12 cántaras de vino, condición que no habían cumplido, por lo cual no estaba dispuesta a entregar la fortaleza a la condesa, que la reclamaba, hasta que no se le hubiesen satisfecho todos los salarios que se le adeudaban ${ }^{57}$.

Al margen de debilitar desde el punto de vista político a los linajes de nobleza media, los repartos sucesorios también tenían efectos negativos sobre su solvencia económica, de modo que para muchos miembros de estos linajes la única alternativa viable para mantener un estilo de vida acorde con su rango consistía en entrar al servicio de alguno de los miembros de la alta nobleza de la región. Éste sería el caso a principios del siglo XVI de Pedro Ruiz de Lezana, señor de la mitad de la villa de Robres, quien, según se hace constar en un interrogatorio de testigos, percibía entonces muy poca renta de su señorío, y vivía «con lo que le daba el duque de Nájera» y lo que había traído al matrimonio su mujer María de Torres. Esto es al menos lo que le interesaba demostrar al propio Pedro Ruiz de Lezana, que estaba litigando con un hermano suyo, que reclamaba que se le diese parte de la mitad de la villa y fortaleza que controlaba él ${ }^{58}$. Sin duda pudo haber parte de exageración para evitar tener que compartir con otros un ya mermado señorío, pero la referencia a la dependencia con respecto a las aportaciones realizadas por el duque de Nájera entendemos que es reflejo de un fenómeno bien real.

\footnotetext{
55 Denuncias del concejo de Quel sobre los agravios que los vecinos recibían de la existencia de cinco señores en AGS, RGS, XI-1518. Provisión al corregidor de Calahorra.

56 Antonio de Gante, señor de parte de Quel, denunció que, estando en esta villa su hijo Juan de Gante, acudieron allí con intención de matarle Diego de Puelles, señor de Autol, y Francisco de Puelles, su hijo mayor, con hasta 200 hombres armados de a pie y a caballo, a los cuales se unió García Sánchez de Alfaro, quien compartía con él el señorío de la villa, al frente de numerosos vecinos de ésta. Y todos juntos arremetieron contra su hijo, que tuvo que buscar refugio en una iglesia, donde lo tuvieron cercado durante dos días y dos noches. AGS, RGS. VII-1520. Comisión al corregidor de Logroño.

57 AGS, RGS, XI-1518. Comisión al corregidor de Calahorra.

58 AChV, P.C. (= Pleitos Civiles), Fernando Alonso, F. (=Fenecidos) C. 1365-1.
} 
A los miembros de la alta nobleza les interesaba contar entre sus servidores con estos caballeros titulares de señoríos de vasallos, que podían aportarles en momentos de necesidad hombres de armas, reclutados entre sus propios vasallos, y facilitarles el control de sus fortalezas, en ocasiones de notable valor estratégico. De ahí que la enconada rivalidad que estos nobles mantenían por la hegemonía política en la región también se trasladase al terreno de la captación de caballeros señores de vasallos para sus clientelas. Y lo cierto es que dichos caballeros no siempre se lo pusieron fácil, pues disponemos de testimonios que prueban que los cambios de señor no fueron fenómenos excepcionales. Un ejemplo paradigmático en este sentido nos lo proporciona el linaje de los Medrano, señores de Almarza y Fuenmayor. En efecto, sabemos que en primer lugar, en la primera mitad del siglo XV, Juan Martínez de Medrano formó parte de la casa del obispo de Calahorra, Don Diego de Zúñiga. Después su hijo Juan de Medrano pasó a incorporarse a la casa del señor de Cameros, Juan Ramírez de Arellano, pero por razones que desconocemos luego se pasó a la casa del duque de Nájera, donde su hijo Hernando de Medrano comenzó a servir a los trece años. A principios del siglo XVI, sin embargo, se planteó un enconado conflicto entre éste y su señor el duque por el control del propio señorío de Fuenmayor, que lindaba con la villa de Navarrete, del señorío del duque ${ }^{59}$, y como consecuencia Hernando de Medrano decidió pasar a servir en la casa del conde de Aguilar, quien le aceptó de buen grado, ganándose así los reproches del duque, quien, según Salazar y Castro, le recriminó manifestándole:

«que no le parecía razón que según el deudo y vecindad que ambos tenían favoreciese el uno los criados que errasen al otro, porque sería darlos atrevimiento para errar $» 00$.

Pero, aunque estos caballeros podían aventurarse por la difícil senda de vincularse en cada momento por lazos clientelares con el señor que más les conviniese, aprovechando las rivalidades existentes entre ellos, no cabe duda de que debían actuar con cautela en este terreno, so pena de resultar severamente represaliados por el señor abandonado, sin recibir el auxilio esperado del nuevo señor. $\mathrm{Y}$, en efecto, los pequeños señoríos que no estaban suficientemente amparados por la protección de un miembro de la alta nobleza corrían un grave peligro de ser objeto de agresión por nobles poderosos. Ya aludimos a esta cuestión al referirnos a los Zúñiga de Las Cuevas, despojados por la fuerza de una fortaleza por el conde de Aguilar, y como complemento podemos citar aquí el caso de la viuda de Íñigo de Medrano, y de sus hijos menores, Diego, Beatriz y Martín de Medrano, a quienes este mismo poderoso noble despojó

59 Noticias sobre las causas y desarrollo del pleito entre Hernando de Medrano y el duque de Nájera por el señorío de Fuenmayor en la ejecutoria que le puso fin en AChV, RE, C. 349, XI1520.

60 SAlazAr y CaStro, Luis de: Historia genealógica de la Casa de Lara, Madrid, 1697, vol. I, p. 125. 
por la fuerza hacia 1486 de la posesión de su torre de Islallana, donde dejó instalada gran cantidad de gente de armas ${ }^{61}$.

Por unos u otros procedimientos lo cierto es que en las últimas décadas del siglo XV y los primeros años del siglo XVI tanto los condes de Aguilar como los duques de Nájera consiguieron colocar bajo su directo dominio, aunque por supuesto no de forma permanente, muchos de los lugares de señorío pertenecientes a nobles de segunda fila de la región, con frecuencia aprovechando las propias rivalidades existentes entre estos últimos cuando eran varios los que compartían el señorío sobre un mismo lugar ${ }^{62}$, o en circunstancias de deterioro de las relaciones entre dichos señores y sus vasallos, como las vividas en Valdezcaray en los últimos años del siglo XV, cuando su señor Pedro Manrique, para presionar a sus vasallos a desistir de continuar con los pleitos que contra él habían iniciado, llegó a ofrecer el señorío al duque de Nájera para que lo tomase en encomienda, aunque no pudo llevar a efecto su propósito porque, en respuesta a una denuncia presentada por los propios vasallos, los reyes lo prohibieron ${ }^{63}$.

\section{INTERVENCIÓN EN LOS MONASTERIOS Y SUS SEÑORÍOS}

La Rioja era una región con muchos e importantes establecimientos monásticos, algunos de los cuales habían sido dotados en los siglos plenomedievales con un importante número de lugares sobre los que ejercían derechos señoriales, destacando en particular desde este punto de vista los de San Millán de la Cogolla y Santa María de Nájera ${ }^{64}$. Para los miembros de la alta nobleza estos señoríos monásticos representaron un campo abonado para sus ambiciones expansionistas, en el que no dudaron en adentrarse en momentos en que la inestabilidad política reinante en Castilla ofrecía mejores oportunidades para la comisión de acciones ilegales con impunidad. Así ocurrió en diversos momentos del siglo XIV, que representó uno de los períodos más difíciles de su historia para los monasterios del norte de Castilla, que perdieron el control sobre muchos de sus señoríos y otras propiedades a manos de nobles ansiosos por incrementar su pode-

${ }^{61}$ AGS, RGS, VII 1486, fol. 39. Comisión al capitán de la frontera, Juan de Ribera, para que obligar a marcharse a la gente armada que estuviese en la torre de Islallana, cerca de Nalda.

${ }^{62}$ Aparte de los ejemplos mencionados hay que destacar en este mismo sentido la intervención del primer conde de Aguilar en el señorío de Robres a fines de la década de 1470, episodio que por su complejidad no podemos entrar aquí a analizar en detalle. Informaciones de interés al respecto en AGS, Cámara-Personas, legs. 11 y 14.

63 Vid. AGS, Cámara-Memoriales, 116-226. Memorial sin fecha de Juan Pardo, en nombre del concejo de Ezcaray y sus cabañas. AGS, RGS, X-1498, fol. 84. Y MonTero TeJADA, Rosa María: «Ideología y parentesco: bases de la actuación política del primer duque de Nájera a comienzos del siglo XVI», Espacio, Tiempo y Forma, 5 (1992), p. 241.

${ }^{64}$ Vid. Diago Hernando, Máximo: «Los señoríos monásticos en la Rioja bajomedieval: introducción a su estudio», Berceo, 131 (1996), pp. 85-107. 
río y sus fuentes personales de ingresos. Como consecuencia a comienzos del reinado de Juan I el número de lugares de señorío monástico que estaban sometidos al control directo de nobles, que se presentaban a sí mismos como sus encomenderos, era muy elevado en todas las regiones septentrionales de la Corona de Castilla, y muy en particular en la Rioja. Y para acabar con esta situación este monarca aprobó en las Cortes de Soria una serie de drásticas medidas que en principio permitieron que la mayor parte de los monasterios recuperasen el control sobre aquellos lugares de su señorío en los que nobles de su entorno habían impuesto encomiendas forzadas ${ }^{65}$.

En la práctica, sin embargo, los monasterios riojanos continuaron estando sometidos a lo largo de todo el siglo XV a las continuas presiones de los linajes de alta nobleza de la región, que con bastante frecuencia intervinieron de forma más o menos violenta en sus asuntos internos. $\mathrm{Y}$, en contra de lo que habría cabido esperar, esta tendencia intervencionista no experimentó ningún freno durante el reinado de los Reyes Católicos, sino que por el contrario entonces se intensificó aún más, en particular tras la muerte de la reina Isabel, cuando los principales representantes de la alta nobleza en la región se lanzaron a una lucha sin freno por el control de los principales monasterios, muy en particular los de San Millán de la Cogolla y Santa María de Nájera, con el objetivo tanto de incrementar su poderío personal como de mermar el de sus rivales.

En el caso de San Millán de la Cogolla sabemos que después de la muerte de la Reina Católica se desató una enconada rivalidad entre los Condestables de Castilla, del linaje Velasco, y los duques de Nájera, del linaje Manrique, para asegurarse la encomienda del monasterio, que atravesaba entonces por una fase de extraordinaria inestabilidad como consecuencia de la oposición ofrecida por importantes sectores de la comunidad monástica a la implantación de la reforma observante propiciada por la monarquía ${ }^{66}$. Esta inestabilidad se tradujo en frecuentes cambios en la dirección del monasterio, en los que se involucraron directamente los mencionados nobles, en unos casos para apoyar a los candidatos con los que simpatizaban y en otros para combatir a aquéllos que consideraban que les eran hostiles.

Así, en el conflicto que a partir de 1504 se desató entre el soriano fray Juan de Soria y el navarro fray Miguel de Alzaga por el control de este monasterio, el duque de Nájera tomó partido de forma decidida en favor del primero, y cuando el segundo consiguió finalmente consolidarse en la dirección de la casa, mientras que fray Juan de Soria era llevado preso a la torre del monasterio de San Salvador de Oña por orden del abad de San Benito de Valladolid, le com-

${ }_{65}$ Vid. SAnTos DíEZ, José Luis: La encomienda de monasterios en la Corona de Castilla. Siglos XXV, Madrid-Roma, CSIC 1961. Y para el caso concreto de los monasterios riojanos, Diago HERNANDO, Máximo : «El intervencionismo nobiliario en los monasterios riojanos durante la Baja Edad Media. Encomiendas y usurpaciones», Hispania, 182 (1992), pp. 811-61.

66 Vid. Diago Hernando, Máximo: «La reforma de los monasterios riojanos en tiempo de los Reyes Católicos», Hispania Sacra, 90 (1992), pp. 667-97. 
batió con todos los medios a su alcance. En concreto durante los años 1506 y 1507 presionó a los vasallos del monasterio para que no le entregasen las rentas, y les sometió a múltiples abusos, por lo que éstos llegaron a solicitar a la monarquía carta de seguro que les pusiese a salvo de sus ataques ${ }^{67}$. Además, durante el año 1508, dirigió reiteradamente memoriales a los órganos de gobierno central de la monarquía en los que solicitaba que fray Juan de Soria fuese liberado de la prisión en que se encontraba y puesto de nuevo al frente del monasterio de San Millán, al tiempo que denunciaba las actuaciones de fray Miguel de Alzaga, que según él habían estado siempre orientadas a perjudicar sus intereses y favorecer los de sus rivales los Velasco ${ }^{68}$. Y sus denuncias se extendieron incluso al juez pesquisidor regio que a principios del año 1507 fue enviado por la monarquía a poner orden en la situación del monasterio de San Millán, el licenciado Bermúdez, de quien sostuvo que en su actuación había favorecido sin ningún disimulo los intereses del Condestable en detrimento de los suyos ${ }^{69}$.

Para disgusto del duque de Nájera, fray Miguel de Alzaga, consiguió mantenerse durante varios años al frente del monasterio de San Millán de la Cogolla, tras obtener una bula en Roma por la que se le designaba abad perpetuo del mismo, y para reforzar su posición trajo de Navarra unos setenta hombres de armas. El duque, sin embargo, no cesó en su empeño por conseguir su expulsión, y el cambio de actitud de fray Miguel de Alzaga en relación a la implantación de la reforma observante en el monasterio, que quedó bien puesto de manifiesto a partir del momento en que aceptó convertirse en abad perpetuo, figura incompatible con el régimen de observancia, que sólo contemplaba la existencia de abades o priores trienales, fue allanándole el camino para finalmente alcanzar su objetivo. Así, en efecto, sabemos que hacia 1510, en circunstancias no del todo bien aclaradas, fray Miguel de Alzaga, sin renunciar a su dignidad de abad perpetuo, abandonó el monasterio para ponerse a salvo en el reino de Navarra. Pero hasta allí le persiguieron sus enemigos, que le causaron la muerte en el transcurso del año 1511, a raíz de ofrecer resistencia cuando iban a proceder a detenerle. La identidad de estas personas que mataron a fray Miguel de Alzaga no nos es bien conocida, pero sí resulta muy revelador el hecho de que el 17 de noviembre del año 1511 fueron absueltos de toda culpa

\footnotetext{
67 AGS, RGS, VII-1507.

${ }^{68}$ Vid. PaCheCo y De Leyva, E.: La política española en Italia. Correspondencia de Don Fernando Marín, abad de Nájera, con Carlos I, Madrid, 1919, docs. 12, 17 y 20.

69 AGS, Cámara-Personas, leg. 19. Memorial del año 1507 de Alonso Romano, procurador del duque de Nájera. Denuncia en concreto que el licenciado Bermúdez, «en las cosas que el Consejo Real le ha comisionado tocantes al duque y su tierra y encomiendas... se ha mostrado parte formada por el Condestable y sus valedores, mandando prender en las tierras del duque los hombres, y tomarles sus bienes de noche con gentes del Condestable. Ha mostrado tener mala voluntad al duque». La comisión al licenciado Bermúdez, alcalde de Casa y Corte, en AGS, RGS, II-1507. Se hace constar que se le había ordenado ir al monasterio de San Millán para «descercarlo» y «derramar» a la gente que allí estaba reunida.
} 
por una carta de perdón otorgada por fray Juan de Amusco, abad de San Benito de Valladolid, quien en ella justificó su acción, argumentando que el navarro se había resistido a su detención y además había cometido graves delitos contra el monasterio de San Millán y la observancia. Fray Juan de Amusco, como veremos, era considerado simpatizante del duque de Nájera, y de ahí que no deje de resultar sospechoso que fuese precisamente él quien otorgó la carta de perdón. Pero los indicios de que el duque pudo estar detrás de la muerte del monje navarro también incluyen una denuncia posterior presentada por el obispo de Calahorra, Juan de Velasco, quien sostuvo que aquél estaba amparando y sosteniendo en Nájera a un clérigo presbítero llamado Joanes de Aguilar, que había espiado a fray Miguel de Alzaga para que lo matasen ${ }^{70}$. Y el interés que este representante de la casa de Velasco mostró por que se castigase a los implicados de una u otra forma en la muerte del abad de San Millán nos confirma que no dejaba de tener razón el duque de Nájera cuando denunciaba que fray Miguel de Alzaga sólo había tratado de favorecer los intereses de los Velasco, que no en vano apoyaban al bando agramontés en Navarra, en el que militaba el belicoso monje de origen navarro.

Una situación muy parecida a la que se vivió en el monasterio de San Millán se reprodujo por estas mismas fechas en el monasterio de Santa María de Nájera, en el que tanto los Manrique como los Velasco ya habían ejercido la función de encomenderos durante el reinado de Isabel la Católica ${ }^{71}$. Tras la muerte de esta reina se recrudeció, sin embargo, la rivalidad entre estos dos linajes por el control de esta comunidad monástica, en concreto a raíz de que el abad de San Benito de Valladolid anunciase su intención de poner al frente de la misma a fray Miguel de Alzaga, quien hacía pocos meses se había hecho también, con el apoyo de este mismo abad, con el control del monasterio de San Millán de la Cogolla, desplazando a fray Juan de Soria. El monje navarro no pudo entonces, sin embargo, hacerse con el control efectivo del monasterio de Santa María de Nájera puesto que a principios del año 1506 un sobrino laico del último abad perpetuo del mismo llamado Fernando Marín, que había conseguido que en Roma se le nombrase abad comendatario de esta casa, consiguió apoderarse del edificio, apresando a algunos de los monjes observantes que habían sido introducidos en la comunidad para promover su reforma.

El duque de Nájera sostuvo que esta entrada violenta de Fernando Marín en el monasterio de Santa María de Nájera a principios del año 1506 había tenido lugar sin su conocimiento y consentimiento, pero muchos indicios invitan a sospechar que no era cierto, y en cualquier caso no se preocupó demasiado por disimular que éste era su candidato favorito para abad. De hecho durante el tiempo en que Fernando Marín estuvo apoderado de este monasterio prestó abiertamente

${ }^{70}$ Tanto la carta de perdón otorgada por fray Juan de Amusco como las denuncias del obispo Juan de Velasco contra el duque en AGS, Consejo Real, leg 27, fol. 9.

${ }^{71}$ Diago Hernando, Máximo: «El intervencionismo nobiliario...» pp. 852 y ss. 
apoyo militar al duque en su intervención en territorio navarro a favor de los beamonteses. Así lo denunciaron en concreto los vecinos de Torrecilla de Cameros, lugar de señorío del monasterio de Nájera, quienes acusaron a Fernando Marín de haberles querido obligar a acudir armados «a punto de guerra» a servir al duque, para ofrecer refuerzos al Condestable de Navarra con ocasión del sitio de la fortaleza de Viana a finales del año $1506^{72}$.

Las instituciones de gobierno central de la monarquía no permanecieron, sin embargo, inactivas, y, dado que el control del monasterio de Nájera por Fernando Marín representaba un importante obstáculo para culminar la empresa de su reforma, finalmente desde éstas se decidió el envío de un juez pesquisidor, el alguacil Lago, para que restableciese en su posición a los monjes observantes que habían sido expulsados. A raíz de ello Fernando Marín debió marchar a Roma, y el duque de Nájera perdió uno de sus principales apoyos en la comunidad monástica najerense. Y buena prueba de que se consideró directamente perjudicado por la actuación del mencionado pesquisidor regio nos la proporciona un memorial que poco después presentó su procurador Alonso Romano en su nombre ante el Consejo Real. En él denunciaba que Juan Lago había metido en el monasterio nueve monjes distintos de los que solían estar en él, los cuales eran «muy sospechosos al duque», mientras que por el contrario no había permitido que regresasen otros monjes que podían ser considerados aliados suyos, como fray Juan de Amusco, natural de esta villa palentina de la que era señor el duque, y fray Alonso de Santoyo, prior segundo, que era natural de este lugar que se encontraba entonces en su encomienda ${ }^{73}$.

Pese a sus constantes maniobras el duque de Nájera no pudo conseguir, sin embargo, recuperar la capacidad de control sobre la comunidad monástica najerense que había tenido durante los meses en que había estado al frente de la misma Fernando Marín. Pero no por ello renunció a tratar de sacar el máximo provecho posible del patrimonio señorial de este monasterio aprovechando cuantas oportunidades se le ofrecieron, como nos testimonian muy en particular los sucesos ocurridos en Torrecilla de Cameros. Era esta villa el lugar más populoso y próspero de cuantos estaban sometidos al señorío del monasterio de Nájera, y ya en 1497 el abad y convento denunciaron que algunos de sus vecinos, para sustraerse a la obediencia que les debían como a sus señores, habían intentado tomar un encomendero que los defendiese, habiéndose planteado

\footnotetext{
72 AGS, RGS, IV-1507. Dos provisiones dirigidas a Don Fernando Marín, abad de Nájera, a petición del concejo de Torrecilla de Cameros. En una se hace constar que éste les había mandado que fuesen con sus armas a punto de guerra a Nájera, y de Torrecilla habían ido 40 peones, a los que se mandó hacer alarde con gente del duque de Nájera. Después se les obligó a ir a Sojuela, y que de allí fuesen a Navarrete para presentarse al duque, para ayudarle a favorecer al Condestable de Navarra, cabeza de los beamonteses. Porque no lo quisieron hacer, Fernando Marín pasó a amenazarles con que les quitaría los alcaldes ordinarios, y les pondría un corregidor de la mano del duque de Nájera.

${ }^{73}$ AGS, Cámara-Personas, leg. 19.
} 
entonces un conflicto entre dos sectores de la población partidarios cado uno de ellos de elegir como tal encomendero a una persona diferente. Nada se aclara en la denuncia sobre la identidad de los dos candidatos a encomenderos, aunque sí hay una confusa alusión al duque de Nájera, por lo que no estimamos improbable que éste fuese uno de los candidatos, y que un miembro del linaje de los Velasco pudiese ser el otro ${ }^{74}$.

Más adelante, ya vimos cómo en 1506 los vecinos de Torrecilla seguían manteniendo una tensa relación con el monasterio, controlado entonces por el abad comendatario laico Fernando Marín, pero tampoco eran cordiales sus relaciones con el duque de Nájera, habida cuenta que se negaron a engrosar el ejército que éste reunía para intervenir en Navarra en apoyo de los beamonteses, a pesar de que se lo había ordenado su señor el abad. Con el paso del tiempo, sin embargo, cambiaron las tornas y así nos lo confirma la denuncia presentada ante las instituciones de gobierno central de la monarquía en 1519 por fray Pedro de Belorado, en nombre del monasterio, contra varios vecinos de la villa de Torrecilla de Cameros, a los que identificó por sus nombres, que en un día de enero de ese año se habían levantado contra el abad y el convento y habían tomado por encomendero y defensor al duque de Nájera, y a su alcalde mayor, Alonso de Barahona ${ }^{75}$.

La alianza del duque de Nájera con los vecinos de Torrecilla fue en cualquier caso de muy corta duración, porque poco tiempo después, habiéndose radicalizado el conflicto que éstos mantenían con su señor, el abad del monasterio de Santa María, éste último, cansado de litigar, terminó por llegar a un acuerdo hacia mediados del año 1522 con el propio duque para venderle la jurisdicción civil y criminal que el monasterio poseía en Torrecilla, que reportaba un beneficio económico muy reducido, por la elevada cantidad de 5.000 ducados y una renta anual de 1.000 fanegas de cereal aproximadamente. Sin duda se trataba de una operación que desde el punto de vista económico resultaba muy rentable para el monasterio, y ruinosa para el duque, pero probablemente éste estaba dispuesto a sacrificar una parte de su capital para hacerse con el control de una villa tan importante, que sin duda le reportaría un notable incremento de su poderío en la comarca. Pero ante esta poco halagüeña perspectiva los vecinos de Torrecilla, que, pese a sus constantes diferencias con los monjes, preferían continuar sometidos al señorío del monasterio antes que pasar a quedar reducidos a la condición de vasallos del poderoso duque, reaccionaron de forma inmediata denunciando ante la monarquía la operación, que

${ }^{74}$ AGS, RGS, XII 1497, fol. 35. Provisión al concejo, alcaldes y hombres buenos de Torrecilla, ordenándoles que no tomasen ningún encomendero.

75 AGS, RGS, II-1519. Provisión dirigida a Alonso de Barahona, alcalde mayor de Nájera, ordenándole que liberase a un criado del monasterio de Nájera a quien había apresado en la plaza de Nájera su lugarteniente, Pedro de Yanguas, en represalia porque el abad del monasterio no había querido devolver las prendas que le habían sido tomadas a Juan Sánchez, merino de Torrecilla de Cameros. 
finalmente no pudo llevarse a cabo porque fue prohibida por provisión real expedida en Palencia el 14 de agosto de $1522^{76}$.

Muchos y de diverso signo fueron, pues, los procedimientos a los que recurrió el duque de Nájera para intentar incrementar su capacidad de control sobre Torrecilla de Cameros, una de las principales villas de señorío monástico de la Rioja, que le llevaron en unas ocasiones a buscar el apoyo del monasterio y en otras el de los vecinos de la villa. Finalmente no pudo alcanzar su objetivo porque lo impidió la monarquía, fortalecida tras su victoria sobre los comuneros, pero la constatación del fenómeno de la implicación del duque en las principales luchas políticas planteadas en esta villa en las dos primeras décadas del siglo XVI nos confirma el interés que para los miembros de la alta nobleza riojana ofrecían los lugares de señorío monástico para ampliar sus bases de ejercicio del poder ${ }^{77}$. Y, teniendo en cuenta esto, resulta más fácil comprender también el empeño que pusieron en conseguir que al frente de los monasterios que ejercían señorío sobre mayor número de vasallos hubiese personas de su confianza.

En el caso de los monasterios femeninos, en los que solían ingresar bastantes más miembros de familias de alta nobleza que en los masculinos, no era infrecuente el caso de que las abadesas fuesen parientas cercanas de algún noble poderoso de la región, que solía aprovechar esta circunstancia para servirse de los lugares de señorío monástico como si fuesen suyos propios. En la región riojana así ocurrió en las últimas décadas del siglo XV y primeras del XVI con el monasterio de Herce, del que entre 1474 y 1501 fue abadesa Leonor de Arellano, hermana del primer conde de Aguilar, y pasó a serlo a partir de este último año su sobrina Juana de Arellano, hija de Carlos de Arellano, señor de Ausejo, Murillo y Alcanadre. Y esta circunstancia sin duda favoreció las constantes intervenciones en la villa de Herce de los condes de Aguilar durante los primeros años del siglo XVI, que reiteradamente trataron de obligar por la fuerza a sus vecinos a que les tomasen como sus encomenderos, aunque en honor a la verdad hay que hacer constar que la abadesa no se avino a prestarles apoyo por el hecho de ser sus parientes, sino que por el contrario les ofreció enconada resistencia, al parecer con escaso éxito.

Así, en 1506, el conde de Aguilar, acompañado por su primo, el señor de Ausejo, Juan de Arellano, hermano precisamente de la abadesa ${ }^{78}$, entraron al frente

${ }^{76}$ AGS, RGS, VIII-1522.

77 Además de Torrecilla de Cameros, también nos consta que el duque de Nájera estuvo en tratos para adquirir por compra la villa de Laguna de Cameros al monasterio de San Martín de Albelda, unido a la colegiata de Santa María la Redonda de Logroño. Vid. PÉrez CARAZO, Pedro: «Laguna de Cameros y sus relaciones con el monasterio de San Martín de Albelda», III Semana de Estudios Medievales, Logroño, Instituto de Estudios Riojanos, 1993, pp. 285-6.

${ }^{78}$ Ese mismo año se denunció que Juan no había entregado todavía los 70.000 mrs. que había prometido a su hermana la abadesa cuando entró en el monasterio. AGS, RGS, VIII-1506. Comisión al corregidor de Logroño. 
de un numeroso grupo de hombres armados en la villa de Herce con el objeto de ocuparla, reaccionando en aquella ocasión la abadesa mediante un recurso a Roma, donde se logró que el Papa Julio II expidiese una bula de excomunión contra el conde ${ }^{79}$, quien también fue reprendido por la monarquía, que en una provisión expedida en enero de 1507 le recordó que ya se le había prohibido con anterioridad que ejerciese la encomienda sobre el monasterio de Santa María de Herce, a pesar de lo cual había entrado con gran cantidad de gente en la villa y tomado por la fuerza la posada de Alonso de Arellano, a quien había intentado matar ${ }^{80}$.

Varios años después, sin embargo, hacia 1512, el conde de Aguilar volvió a entrar en la villa de Herce, consiguiendo, mediante la mediación de Miguel de Vidaurreta, un criado suyo que residía allí, que algunos de sus vecinos le jurasen como su encomendero, mientras que los criados y servidores de la abadesa que se negaron a hacerlo y no se incorporaron a su "parcialidad» fueron obligados a huir de sus casas, perdiendo gran parte de sus bienes ${ }^{81}$. Y, al margen de estas intervenciones orientadas a imponer su encomienda sobre la villa, también tenemos noticia de algunas otras, de carácter igualmente violento, que tuvieron por objetivo favorecer los intereses de miembros de su clientela que residían allí. Así lo denunció, por ejemplo, en 1512 la viuda del alguacil de Herce, Pedro de Quirós, quien declaró que, habiendo hecho ejecución su difunto marido por mandado de la justicia de la villa en 35 fanegas de trigo propiedad de Francisco de Vidaurreta, criado del conde de Aguilar, éste entró por la fuerza en Herce y contra la voluntad de su marido tomó el trigo y lo devolvió a Francisco de Vidaurreta ${ }^{82}$.

Todas estas noticias no dejan lugar a dudas sobre la fuerte presión a la que estuvieron sometidos los lugares de señorío monástico en la Rioja a principios del siglo XVI. Y, aunque los tres monasterios a los que hemos hecho referencia hasta ahora fueron sin duda los que sufrieron un mayor acoso, en el caso de San Millán y de Santa María de Nájera como consecuencia de la rivalidad desatada entre los Manrique y los Velasco por conseguir su control, y en el de Santa María de Herce por razón de la consideración cuasi-patrimonial que del mismo llegaron a tener los Arellano, lo cierto es que los demás no quedaron tampoco libres de esta plaga. Y como prueba sirva recordar la denuncia presentada en 1505 por el monasterio de San Prudencio contra Juan Ramírez de Arellano, hijo del conde de Aguilar, y Juan de Fuenmayor, vecino de su villa de Albelda, a quienes acusó de tenerle ocupados muchos de sus términos ${ }^{83}$.

79 Vid. Diago Hernando, Máximo:»Un monasterio cisterciense femenino en tierras riojanas. Herce entre los siglos XIII y XVI», Cistercium, 188 (1992), p. 140.

80 AGS, RGS, I-1507. Provisión al conde de Aguilar.

81 AGS, RGS, V-1512. Dos provisiones dirigidas al corregidor de Logroño. En una de ellas se hace referencia explícita a las acusaciones presentadas por Diego de Urlenes, vecino de Herce, merino por la abadesa, contra Miguel de Vidaurreta, que entonces era alcaide de Arnedillo.

82 AGS, RGS, XII-1512. Provisión al corregidor de Calahorra, a petición de Constanza de La Bastida, vecina de Herce.

83 AGS, RGS, V-1505, fol. 231. 


\section{PRESENCIA DE LOS LINAJES DE ALTA NOBLEZA EN OTRAS INSTITUCIONES ECLESIÁSTICAS: LA SEDE EPISCOPAL Y EL CABILDO CATEDRALICIO DE CALAHORRA}

La utilización de las instituciones eclesiásticas por los representantes de la alta nobleza en la Rioja para el incremento de su poderío personal en la región no quedó limitada a las intervenciones en los monasterios y sus señoríos de las que acabamos de dar cuenta. También despertaron su interés otras instituciones como las sedes episcopales o los cabildos catedralicios, el control de las cuales podía proporcionarles igualmente constantes oportunidades para intervenir activamente en la vida política del conjunto de la región, o de alguna de sus ciudades en particular, aunque por mecanismos diferentes a los puestos en práctica en los monasterios.

En efecto, en claro contraste con las grandes comunidades monásticas riojanas, ni la sede episcopal de Calahorra-La Calzada ni los cabildos catedralicios de las dos ciudades que compartían la capitalidad de la diócesis, llegaron a acumular un importante patrimonio señorial, que pudiera ser objeto de usurpación por los nobles del entorno. Pero, aunque este patrimonio fue muy reducido, no por ello dejó de despertar las apetencias de algunos de estos nobles. Y así nos lo demuestra, por ejemplo, la denuncia presentada en el año 1502 por el concejo de Inestrillas, villa perteneciente al señorío de la mesa episcopal de Calahorra, la cual había sido tomada en encomienda, en un momento en que la sede se encontraba vacante, por el conde de Aguilar, quien desde entonces trataba a los vecinos como si fuesen sus propios vasallos ${ }^{84}$.

La capacidad para el ejercicio del poder de que disfrutaban los obispos de Calahorra derivaba, sin embargo, sólo en muy pequeña medida de su condición de señores de vasallos, pues en su caso resultaban mucho más relevantes desde este punto de vista las atribuciones que les confería el ejercicio de la jurisdicción eclesiástica, a pesar de que éstas también estaban bastante limitadas en este obispado, y muy en particular en algunas de sus comarcas, como, por ejemplo, el señorío de Vizcaya. Con todo, el derecho canónico ponía en manos de los obispos unos instrumentos que les conferían notable autoridad no sólo sobre los miembros del estamento clerical de su diócesis sino también sobre los laicos. Y, aunque estos instrumentos estaban preferentemente pensados para asegurar el recto gobierno de la Iglesia en materias de naturaleza espiritual, lo cierto es que con bastante frecuencia fueron utilizados como armas en el combate político, en el que estaban involucrados tanto laicos como clérigos.

Así se puso bien de manifiesto en el territorio riojano durante el breve período de tiempo en que la sede de Calahorra-La Calzada estuvo ocupada a principios del siglo XVI por un miembro del linaje Velasco, que sin ningún tipo de reparo se sirvió de los instrumentos que ponía a su disposición su condición de obispo para la persecución de los objetivos políticos de su linaje, en la larga

\footnotetext{
${ }^{84}$ AGS, RGS, XII-1502.
} 
pugna que mantenía con el linaje Manrique por alcanzar la hegemonía en determinadas regiones del norte de Castilla. Nos referimos a Juan de Velasco, hermano del Condestable Bernardino Fernández de Velasco, y de su sucesor Ínigo Fernández de Velasco, que heredó su mayorazgo a su muerte sin hijos varones en el año 1512. Fue nombrado obispo de Calahorra a comienzos de 1509, tras la promoción de D. Fadrique de Portugal a la iglesia de Segovia, y muy poco tiempo después se vio inmerso en un enconado conflicto con el duque de Nájera, el antagonista por antonomasia de su linaje, en el transcurso del cual tuvieron lugar ayuntamientos de gente de armas por ambas partes que obligaron a la monarquía a intervenir para evitar el derramamiento de sangre mediante el envío en el transcurso del año 1511 como juez pesquisidor, con orden de derramar las tropas que se hubiesen reunido, del comendador Sebastián de Arroyo ${ }^{85}$.

Al parecer el conflicto se desató a raíz de haber exigido el obispo Juan de Velasco al duque de Nájera que devolviese gran cantidad de objetos de uso litúrgico de oro y plata que había tomado por la fuerza a las iglesias del condado de Treviño y otras iglesias del obispado, y haberse negado el duque a hacerlo con el argumento de que las tomas se habían efectuado por orden de los Reyes Católicos para financiar la guerra contra el rey de Portugal. Y un segundo motivo de desavenencia entre ambos que se añadió más adelante a éste fue el derivado de la negativa del duque a entregar a un clérigo presbítero llamado Joanes de Aguilar, considerado responsable de la muerte violenta del abad de San Millán de la Cogolla, fray Miguel de Alzaga.

Estos dos motivos alegados por el obispo Velasco para justificar sus actuaciones contra el duque de Nájera ponen bien en evidencia el carácter esencialmente político del conflicto, que hundía sus raíces en rivalidades personales y de linaje, pues, en primer lugar, no deja de resultar sospechoso que la exigencia de devolución del oro y plata presuntamente tomados por la fuerza en las iglesias del condado de Treviño se presentase unos 35 años después de haber tenido lugar el hecho, sin que ninguno de los tres obispos que habían precedido a Juan de Velasco en la sede hubiese prestado atención ninguna a este asunto. Y, por lo que toca al segundo motivo que desencadenó el conflicto, la negativa a la entrega del clérigo Joanes de Aguilar, resulta bastante evidente que el interés del obispo Juan de Velasco por castigarle obedecía al hecho de que se le consideraba responsable de la muerte violenta de fray Miguel Alzaga, quien, como hemos visto, había sido uno de los principales valedores de la casa de Velasco en la Rioja en las décadas previas, y acérrimo enemigo del duque de Nájera.

Por razones que poco tenían que ver con el recto gobierno de las almas de los fieles, y mucho más con el enfrentamiento banderizo que desde hacía décadas venían protagonizando las casas de Velasco y Manrique en la Rioja, el obis-

85 Para la reconstrucción de este conflicto nos basamos en la información tomada por el pesquisidor regio enviado en 1512, que se conserva en AGS, Consejo Real, leg. 27, fol. 9. También aportan noticias de interés numerosas provisiones, sobre todo del año 1512, conservadas en AGS, RGS. 
po Juan de Velasco, a los pocos meses de haber tomado posesión de la sede, en el transcurso del año 1511, decretó el entredicho y la cesación de los divinos oficios en todas las iglesias sujetas a su jurisdicción que se encontrasen en tierras de señorío del duque de Nájera, sirviéndose de este modo de un instrumento propio de la jurisdicción eclesiástica para luchar contra un enemigo laico con el que mantenía diferencias que en muy escasa medida afectaban a negocios de la Iglesia. La reacción inmediata del duque fue ordenar a los clérigos de sus lugares de señorío que no observasen el entredicho y continuasen celebrando con normalidad los divinos oficios, y tomar medidas de represalia contra aquéllos que se negasen a obedecer esta orden. A partir de ahí las posturas se fueron radicalizando en ambas partes, y fueron tomando un cariz cada vez más violento, puesto que el obispo Juan de Velasco no se limitó a blandir armas de carácter espiritual para combatir a su rival, sino que, utilizando como base de operaciones la villa de Haro, de la que era señor su hermano el Condestable, puso en marcha una campaña de reclutamiento masivo de tropas entre los seguidores de su linaje en la región que se extendía entre Burgos y Nájera, y también recurrió a otros procedimientos de intimidación que conllevaron el uso de la violencia física ${ }^{86}$.

Por falta de espacio no podemos entrar aquí a dar cuenta más detallada de las vicisitudes de este singular conflicto que desestabilizó la región riojana en los años 1511 y 1512, pero con lo dicho basta para advertir cómo las sedes episcopales podían proporcionar a los linajes de alta nobleza una importante baza para incrementar su poderío en un ámbito regional determinado. En la Rioja, sin embargo, en la época que analizamos este fenómeno sólo se dio durante un período muy limitado de tiempo, la segunda década del siglo XVI, cuando ocupó la sede de Calahorra-La Calzada un miembro de un linaje con fuerte implantación en la región, pero en fases anteriores ya habían tenido lugar fenómenos comparables, por ejemplo durante la primera mitad del siglo $\mathrm{XV}$, cuando fue obispo Diego de Estúñiga, quien desplegó una intensa actividad política en la región ${ }^{87}$.

Además de la sede episcopal, también los cabildos de las catedrales de Calahorra y Santo Domingo de la Calzada ofrecieron a los linajes de alta nobleza riojana una útil plataforma para reforzar su autoridad e influencia en el ámbito político regional mediante la colocación de algunos de sus miembros en posi-

\footnotetext{
${ }^{86}$ Juan de Orduña, vecino del condado de Treviño, denunció que cuando había ido a notificar al obispo una apelación interpuesta por los clérigos del condado de Treviño del entredicho que éste había mandado poner, le preguntó si la apelación era del duque, y tras responderle que sí le amenazó con mandarle ahorcar. Y acto seguido Julián de Lezano y el alcaide de Haro, le apresaron y le llevaron a la fortaleza de la villa de Haro, donde le metieron en una mazmorra, en la que le echaron grillos, y le tuvieron atado día y noche. Después el obispo dio una sentencia contra él para que le matasen, pero después, a súplica de unos frailes, le mandó soltar, amenazándole con que si volvía por allí le mandaría matar. AGS, RGS, XII-1511. Comisión al comendador Sebastián de Arroyo.

87 Vid. Diago Hernando, Máximo: «Linajes navarros en la vida política regional...», pp. 569 y ss.
} 
ciones dirigentes dentro de los mismos. Por lo que de momento sabemos este fenómeno apenas alcanzó relevancia en el caso de la catedral de Santo Domingo de la Calzada, pero no ocurrió así en la de Calahorra, puesto que durante todo el período que aquí estamos analizando estuvo al frente de su cabildo, ocupando la dignidad de deán, un hermano del conde de Aguilar, don Diego de Arellano ${ }^{88}$, quien participó activamente en la vida política de esta ciudad de realengo de la Rioja Baja, esforzándose en todo momento por conseguir que miembros de su clientela ocupasen algunos de los principales oficios de gobierno concejil ${ }^{89}$. Sus relaciones con otros miembros de su linaje fueron, sin embargo, de signo contradictorio. Así por un lado constatamos que a algunos, como su hermano Fadrique de Arellano, les facilitó la entrada en Calahorra al frente de sus clientelas de hombres armados, en contra de la opinión de los gobernantes laicos de la ciudad, que la consideraban como una grave amenaza para el orden público ${ }^{90}$. Pero por otro lado mantuvo un enconado y prolongado conflicto con su pariente el señor de Ausejo, Murillo y Alcanadre, Juan de Arellano, por la abadía de la villa de Alcanadre, que dio lugar a varios episodios violentos ${ }^{91}$, y llevó a que el deán recurriese a la socorrida fórmula de imponer el entredicho como medida de presión ${ }^{92}$.

\section{ESTABLECIMIENTO DE RELACIONES DE CLIENTELA CON MIEMBROS DE LAS OLIGARQUÍAS DE LAS CIUDADES DE REALENGO}

Según ya hemos adelantado, las ciudades riojanas, aunque fueron núcleos muy dinámicos desde el punto de vista económico, no demostraron idéntica

\footnotetext{
88 Ocupó la dignidad de deán hasta el año 1520 en que consiguió traspasarla a su pariente Carlos de Arellano, quien presentó bulas de provisión del deanazgo expedidas en Roma en su favor en sesión de cabildo de 24-XI-1520. También ocupó una importante dignidad en este cabildo otro miembro de este mismo linaje, Álvaro de Arellano, quien tomó posesión del arcedianazgo de Nájera el 12-IX-1512, según consta por el libro de actas del cabildo.

89 Vid. Diago Hernando, Máximo: «Clérigos y laicos en la lucha por el poder en la ciudad de Calahorra a fines de la Edad Media: Los conflictos entre los oficiales del concejo y el cabildo de la catedral», Berceo, 148 (2005), pp. 93-124.

90 Sobre los disturbios que tuvieron lugar con ocasión de la entrada en Calahorra por Fadrique de Arellano en un día de mayo de 1508, acompañado por mucha gente armada, Vid. CámaraPersonas, leg. 2-233.

${ }^{91}$ Por ejemplo en 1518 se denunció que Sebastián de Vidaurreta, alcaide de Ausejo, y otros criados y vasallos de Juan de Arellano dieron de palos al vicario del obispo de Calahorra, y a otros clérigos, y a un procurador del deán, cuando fueron a hacer ciertos autos de justicia a la villa de Alcanadre. AGS, RGS, VII-1518. Provisión dirigida a Juan de Arellano.

92 Entre otras referencias Vid. AGS, RGS, IV-1520. Comisión a Diego Fernández de Valera. Se hace constar que por razón del pleito pendiente entre el deán Diego de Arellano y D. Juan de Arellano, señor de Alcanadre, sobre la abadía de esta villa, estaba puesto entredicho en todo el obispado, y como consecuencia tanto clérigos como laicos sufrían un gran perjuicio y daño.
} 
capacidad para desempeñar un papel de primera fila en la vida política regional, y menos aún en la del conjunto del reino, entre otras razones porque estuvieron dotadas de cortos términos, y pronto se vieron por consiguiente rodeadas de señoríos nobiliarios que terminaron aprisionándolas. Durante el siglo XV la mayoría de estas ciudades fueron por otra parte víctimas de un sistemático acoso perpetrado por los principales representantes de la alta nobleza en la región, que trataron por todos los medios de someterlas a su señorío, y en algunos casos terminaron consiguiéndolo, como ocurrió en Haro, concedida por Juan II en 1430 a Pedro Fernández de Velasco, y más tarde en Nájera, concedida por Enrique IV en 1465 a Pedro Manrique, y tomada a la fuerza por las tropas de éste al año siguiente ${ }^{93}$.

Los pocos núcleos urbanos que consiguieron permanecer en el realengo, en concreto Santo Domingo de la Calzada, Logroño, Calahorra y Alfaro, adoptaron por consiguiente durante el reinado de los Reyes Católicos una sistemática política defensiva que se marcó como principal objetivo mantener alejados de ellas a los miembros de la alta nobleza, e impedir por todos los medios a su alcance que se pudiesen inmiscuir en sus asuntos internos. Para ello pusieron especial cuidado en impedir que dichos nobles, o miembros de sus familias, o incluso caballeros notables que formasen parte de sus clientelas, llegasen a fijar en ellas su residencia, como bien lo testimonian los varios pleitos en que en los primeros años del siglo XVI se embarcaron las ciudades de Santo Domingo de la Calzada y Logroño para impedir que adquiriesen casas en las que poder fijar su residencia miembros de los linajes Velasco, Arellano y Leiva ${ }^{94}$.

$Y$, en efecto, los temores a los efectos nocivos que la residencia de miembros de familias de la alta nobleza podía tener para la vida política local de estas ciudades estaban fundados, pues sabemos de los desórdenes que en ocasiones provocó la mera presencia ocasional de alguno de ellos en las mismas, incluso cuando su intención no era otra que tomar parte en la celebración de algún acto festivo. Así ocurrió, por ejemplo, en Logroño en el año 1518 con ocasión de la entrada en la ciudad del conde de Aguilar para asistir a una fiesta que allí se celebraba durante las ochavas de la Pascua de Pentecostés ${ }^{95}$. En efecto, a pesar de que el concejo logroñés había ordenado pregonar que nadie osase llevar armas en la ciudad, algunos de los mozos de espuelas que formaban parte de la comitiva del conde las llevaron consigo durante esta visita, por lo que el alguacil mayor de Logroño y su teniente se apresuraron a tratar de quitárselas, aunque sin éxito, ante la resistencia de los mozos. Como consecuencia se desencadenó un

${ }_{93}$ Más detalles acerca de las presiones ejercidas por la alta nobleza sobre las ciudades riojanas a lo largo del siglo XV en GoicolEa Julián, Francisco Javier: El gobierno urbano en la Rioja en época medieval e inicios de la Edad Moderna (s. XIII-mediados del XVI), Logroño, Instituto de Estudios Riojanos, 2004, pp. 76 y ss. Y Diago HernANDO, Máximo: «Política y guerra...»

${ }^{44}$ Noticias sobre estos pleitos en Diago Hernando, Máximo: «Conflictos políticos y sociales...», p. 65. Y Goicolea Julián, Francisco Javier: El gobierno urbano... pp. 99-100.

95 AGS, RGS, VI-1518. Provisión al corregidor de Logroño. 
enfrentamiento armado entre los alguaciles y sus hombres, de un lado, y los criados del conde, de otro, del que resultaron algunos heridos. Poco después acudieron en auxilio de los criados del conde dos hermanos de éste, además de varios de sus continos y criados, todos los cuales se pusieron a perseguir al teniente de alguacil, a quien hirieron en una pierna. Y el desafortunado episodio finalizó con la detención de los hermanos del conde y varios de sus seguidores.

Otro alboroto de parecido signo había tenido lugar años antes, en 1508, en la ciudad de Calahorra a raíz de la entrada en ella de otro miembro del linaje Arellano, Don Fadrique, hermano del deán de la catedral, quien en principio no tenía otra intención que realizar unas «albadas», rondas nocturnas con acompañamiento musical a varias damas de la $\operatorname{ciudad}^{96}$. El teniente de corregidor, sin embargo, no quiso consentirle que entrase con gente armada en Calahorra, mientras que él insistió en su derecho a poder hacerlo, alegando que la llevaba consigo para su defensa, y como consecuencia se puso en marcha una sucesión de graves disturbios, dado que el teniente de corregidor llegó a juntar unos 60 hombres de armas para forzar a Don Fadrique a que desistiese de continuar celebrando las «albadas», aunque finalmente no se llegó al enfrentamiento armado y no hubo víctimas que lamentar. Pero el alboroto al que dio lugar una cuestión en principio banal vino a poner de manifiesto hasta qué punto los gobernantes de las ciudades realengas riojanas recelaban de las familias de alta nobleza con fuerte implantación en la región, y trataban por consiguiente por todos los medios de mantenerlas alejadas para evitar incidentes. Y, siguiendo con el ejemplo de Calahorra, esta misma impresión nos transmite la constatación de la reacción del concejo calagurritano en el otoño del año 1520 cuando, en pleno conflicto comunero, el conde de Aguilar le envió una carta en la que anunciaba su intención de acudir en persona a la ciudad a entender en ciertos negocios, pues, en términos por supuesto muy respetuosos, le rogaron que desistiese de hacerlo por «quitar las diciones que se podrian decyr de la venida de Vuestra Señoría»97.

Lo dicho hasta ahora podría hacernos pensar que los todopoderosos nobles de los linajes Arellano, Velasco y Manrique, que no tuvieron grandes dificultades para someter a su autoridad monasterios, cabildos y señores de vasallos de

\footnotetext{
${ }_{96}^{6}$ En los relatos del suceso se dice que Don Fadrique de Arellano en una noche de mayo hizo armar mucha gente y con mucho alboroto y tiros de pólvora, por fuerza y contra voluntad de la justicia, entró en la ciudad, y fue por algunas calles de la misma, «haciendo muchas ofensas e injurias y disfamias contra muchas mujeres casadas y doncellas, y otros insultos dignos de mucho castigo». En otro lugar, sin embargo, se aclara que Don Fadrique "concertó de andar por la ciudad en una noche de mayo dando albabas en ciertas casas de la ciudad con música y cantores». Y para dar más solemnidad al acto sacó los órganos de la catedral, con permiso de su hermano el deán, y mandó sacar de la iglesia de San Sebastián «los servidores de los tiros de pólvora de artillería para tirar por las calles truenos con ellos». AGS, Cámara-Personas, leg. 2-233.

${ }_{97}$ Carta del concejo de Calahorra al conde de Aguilar, fechada en Calahorra, 12-X-1520, publicada por Gutiérrez ACHútegui, Pedro: «Documentos interesantes para la historia de Calahorra y la general de España», Berceo, 19 (1951), pp. 250-8, doc. IV.
} 
la pequeña nobleza rural, chocaron en las murallas de las ciudades realengas con una barrera que puso un límite infranqueable a su poderío. Nada más lejos, sin embargo, de la verdad, puesto que sabemos por el contrario que durante períodos más o menos prolongados de tiempo estuvieron apoderados de algunas de estas ciudades, como fue el caso, por ejemplo, de Logroño, que estuvo en unos momentos bajo el dominio de los Manrique ${ }^{98}$ y en otros bajo el de los Arellano99. Y por su parte Santo Domingo de La Calzada llegó a ser concedida en señorío por Enrique IV al Condestable, quien no pudo sin embargo apoderarse de ella porque se lo impidió su rival el conde de Treviño, luego duque de Nájera ${ }^{100}$. Tras el acceso al trono de los Reyes Católicos ciertamente estas situaciones ya no se repitieron, pero la ausencia física de los nobles de dichas ciudades no se tradujo en una pérdida radical de influencia, sino que por el contrario ésta la mantuvieron por otros múltiples mecanismos.

Así, por ejemplo, en Logroño los condes de Aguilar, después de abandonar por imperativo regio en fecha posterior a 1475 la ciudad, que años antes habían tomado por orden de Enrique IV ${ }^{101}$, continuaron ejerciendo una fuerte influencia en la vida política de la misma, según nos testimonia un documento del año 1492 en el que se sostenía que era el conde quien gobernaba allí de hecho ${ }^{102}$. Y uno de los mecanismos principales del que tanto ellos como sus rivales los Velasco y los Manrique se sirvieron para fundamentar dicha influencia fue el de la integración en sus clientelas de vecinos de estas ciudades, que desempeñaban oficios de gobierno, a los que pagaban acostamiento. Por supuesto se trataba de una práctica que había quedado terminantemente prohibida en todo el reino por una pragmática de los Reyes Católicos, pero las reiteradas

${ }_{98}$ Logroño estuvo en poder del Adelantado Diego Manrique, primer conde de Treviño, a principios de la década de 1440, aunque finalmente los vecinos lograron expulsarle por la fuerza de ella. Vid. Diago Hernando, Máximo: «Política y guerra...» p. 534.

99 Sobre la posesión de Logroño por el conde de Aguilar Vid. AGS, EMR, leg. 37, fol. 376. Provisión de RRCC de Palencia 19-IX-1475. Se indica que el conde había informado que «él gastó muchas cuantías por mandado del rey Enrique en la toma de Logroño, que él tomó para su servicio, y en la guardia que en ella ha tenido hasta hoy día». En 1505 Juan de Marquina sostuvo en un memorial que «al tiempo que los çibdadanos tenían los ofiçios procuraron traer a la çibdad al conde de Aguilar, quien se apoderó de la çibdad». AGS, Cámara-Pueblos, leg. 10, Logroño. Por fin GoicoleA Julián, Francisco Javier: El gobierno urbano en la Rioja... p. 80, cita un documento en que se afirma lo siguiente: «que el dicho conde de Aguilar pasado entro en la dicha çibdad y se apodero en ella y çerro las torres de la puerta del camino y puso por alcayde a Juan de Çuñiga y nunca quiso salir de la dicha çibdad fasta que sus altesas gelo mandaron y tomo en aquel tiempo las varas de la justiçia de ella».

100 Así se hace constar en AGS, Cámara-Personas, leg. 19, Testimonio presentado por el procurador del duque de Nájera en Uruñuela, 10-IV-1500. Se hace referencia al hecho de que «aviendo el duque mi señor en los tiempos pasados defendido a Santo Domingo de la casa del Condestable que procuró merçed della del rey don Enrique y procuraba de la tomar, que más rasón era que los hijos del que la defiende entrasen en Santo Domingo que non del que la quiso tomar»

${ }_{101}$ Cfr. nota 99.

102 AGS, RGS, IX-1492, fol. 211. 
denuncias de la inobservancia de la misma, que llegan en el caso de Logroño hasta el año $1522^{103}$, demuestran que ésta no representó un obstáculo importante para ponerle freno.

Los condes de Aguilar contaron, en efecto, entre sus criados a fines del siglo XV y comienzos del siglo XVI con vecinos de Logroño, entre los que cabe destacar a su contador Martín González de Yanguas, quien se vio involucrado en agrios conflictos con el concejo logroñés en vísperas de la revuelta comunera que no podemos entrar aquí a analizar con detalle. Pero también sus rivales los duques de Nájera reclutaron en esta ciudad a miembros destacados de sus clientelas, como es el caso, por ejemplo, de Cristóbal Moreno, individuo que desempeñó un activo papel en la vida política logroñesa en los primeros años del siglo $\mathrm{XVI}^{104}$. Y al margen de ciudadanos de cierto relieve político, estos poderosos nobles, así como los Condestables, señores de la villa de Haro, reclutaron en Logroño a numerosos individuos para que les sirviesen como hombres de armas a cambio de recibir el correspondiente acostamiento. Así nos lo pone de manifiesto un documento del año 1498 en que los Reyes Católicos manifestaban que habían sido informados de que el Condestable y el duque de Nájera «a causa de sus diferencias han tomado de pocos días aca y toman de nuevo muchos vecinos de la ciudad de Logroño y su comarca de vivienda y en encomien$\mathrm{da}$, a causa de lo cual se esperan seguir algunas diferencias e inconvenientes» ${ }^{105}$. Pero, aunque estos monarcas enviaron entonces como pesquisidor al doctor Alonso Escudero para que se informase y pusiese fin a esta peligrosa situación, lo cierto es que muchos caballeros y escuderos de la ciudad de Logroño, e incluso también de las de Alfaro y Calahorra, continuaron viviendo de acostamiento con el Condestable o con el duque de Nájera, y en 1501 acudieron con sus caballos y armas a los llamamientos de sus señores, forzando de nuevo la intervención de los reyes para evitar un inminente derramamiento de sangre ${ }^{106}$.

Estos reclutamientos masivos de gente de acostamiento entre la población de las ciudades realengas riojanas, sobre todo cuando los reclutados eran individuos que desempeñaban oficios de gobierno local, provocaban un evidente debilitamiento de las instituciones de gobierno urbano, porque, según se hacía saber a los reyes en las solicitudes que reiteradamente se presentaban para que se cumpliese la pragmática que prohibía estas prácticas, los oficiales que vivían

103 Vid. AGS, RGS, XII-1503 y I-1522. Provisión al corregidor de Logroño, en respuesta a la denuncia presentada por Lope Rodríguez, vecino de Logroño, haciendo saber que en Logroño había personas que estaban en el concejo y vivían con señores. AGS, RGS, I-1522.

104 Vid. Diago Hernando, Máximo: «Conflictos estamentales por el control del gobierno municipal en Logroño a fines del XV y principios del XVI», Cuadernos de Estudios Medievales y CC y TT Historiográficas, 17 (1992), pp. 213-5. Se confirma que era criado del duque de Nájera en AGS, RGS, IX-1496, fol. 102.

105 AGS, RGS, VIII 1498, fol. 171.

106 AGS, RGS, VII-1501. Comisión al corregidor de Logroño, Alfaro y Calahorra para que castigase a los culpables de haber desobedecido la prohibición de acudir a tales llamamientos. 
con señores guardaban más lealtad a éstos que a su ciudad. Pero los subterfugios a los que se recurría para incumplir en la práctica la pragmática, sin por ello incurrir en las penas contempladas en ella, eran muchos, y así nos lo pone de manifiesto, por ejemplo, la denuncia presentada en 1511 contra algunos regidores de Calahorra, acusados de estar cometiendo el fraude de poner a sus mujeres e hijos menores de edad para que llevasen acostamientos del deán y del chantre de la Iglesia, y de otros caballeros, a fin de poder ellos continuar ejerciendo sus oficios ${ }^{107}$.

\section{CONCLUSIÓN}

La Rioja era a fines del Medievo una región en la que, pese a la pujanza económica de sus núcleos urbanos, desde los que operaban dinámicas comunidades de mercaderes, que participaban en negocios de exportación fuera de la Península, el peso político de los linajes de alta nobleza era aplastante, pues, además de ejercer el señorío directo sobre extensos territorios, habían conseguido por diversos procedimientos extender su influencia a otros muchos lugares de la región, que formaban parte del realengo y del abadengo, o tenían como señores a miembros de la pequeña nobleza rural. Ninguno de estos linajes había conseguido para entonces, sin embargo, dominar una parcela del espacio político riojano suficientemente amplia como para poder erigirse en instancia hegemónica indiscutible del mismo, sino que por el contrario eran varios los que estaban en condiciones de disputarse su dominio, por disponer de bases suficientes para ello. Y como consecuencia los conflictos banderizos entre estos linajes terminaron por convertirse en endémicos, contribuyendo así a mantener la vida política regional en un estado de constante inestabilidad, que ya resultó bastante perceptible en vida de la reina Isabel la Católica, y se agravó aún más tras su muerte, prolongándose hasta el estallido de la revuelta comunera, cuando los representantes de la alta nobleza, alarmados por los levantamientos antiseñoriales ocurridos en Nájera y en Haro, olvidaron viejas rencillas y formaron frente común para apoyar la causa del rey, como bien pone de manifiesto el apoyo que el Condestable prestó a su viejo rival el duque de Nájera para reprimir la revuelta de sus díscolos vasallos najerenses ${ }^{108}$.

Los dos grandes conflictos banderizos que coexistieron en territorio riojano en las dos últimas décadas del siglo XV y las dos primeras del siglo XVI fueron el que opuso al linaje de los Manrique con el de los Velasco, por un lado, y el que enfrentó al mismo linaje Manrique con el de los Arellano, por otro. Por supuesto no siempre resulta posible deslindar con absoluto rigor un conflicto

107 AGS, RGS, XII-1511. Provisión al corregidor de Calahorra, ordenando que se prohíba que mujeres e hijos «chiquitos», que estén bajo el poderío paterno, puedan llevar acostamientos.

108 Vid. MaLdonado, Ramón José, art. cit. 
del otro, puesto que en determinadas ocasiones los Arellano y los Velasco colaboraron contra su enemigo común, por ejemplo en sus intervenciones militares en el reino de Navarra, donde ellos apoyaron al bando agramontés, mientras que los Manrique prestaban su auxilio al bando beamontés. Pero en líneas generales las desavenencias que cada uno de estos linajes mantenían con los Manrique obedecían a razones diferentes, y por consiguiente los enfrentamientos derivados de las mismas se desarrollaron en gran medida independientemente el uno del otro. De hecho el enfrentamiento entre los Velasco y los Manrique era de bastante más envergadura porque afectó a otras regiones de la Corona de Castilla, como la actual provincia de Palencia y las provincias vascongadas.

En este último territorio los conflictos banderizos llegaron a alcanzar también en algunos momentos del siglo XV extrema gravedad, pero, a diferencia de lo que ocurrió en la Rioja, ya durante el reinado de los Reyes Católicos desaparecieron o entraron en proceso de irremisible decadencia, según Díaz de Durana $^{109}$. Este fue un logro, no obstante, que cabe atribuir conjuntamente a los hidalgos rurales y a los vecinos de las villas de las provincias vascongadas, que consiguieron hacerse con el control de los nuevos órganos de gobierno «provincial» puestos en marcha por las Hermandades, de los que fueron radicalmente apartados los representantes de la alta nobleza, allí llamados «Parientes Mayores». Y aquí radicó la gran diferencia entre estas provincias y la Rioja, que a partir del siglo XVI evolucionaron por dos sendas completamente divergentes, puesto que mientras que en las primeras se consolidaron sociedades políticas provinciales bien cohesionadas, dotadas de órganos de representación sin paralelo en otros ámbitos de la Corona de Castilla, en los que la población de las ciudades mantenía una notable influencia, la Rioja continuó siendo un territorio fragmentado, carente de identidad como «provincia». Y buena prueba de ello es que su representación en Cortes fue asumida por las ciudades de Burgos y Soria, quedando por lo tanto a este efecto dividido su territorio en dos sectores. Por su potencial demográfico y económico varias de las ciudades realengas riojanas podían bien rivalizar con esta última capital castellana, pero en lo que ésta las aventajaba era en su superior rango político, derivado del hecho de que ejercía la jurisdicción civil y criminal sobre un extenso territorio y estaba gobernada por un grupo oligárquico muy reducido, con un fuerte componente noble, que mantenía estrechos vínculos con la monarquía. Por estos y otros motivos la ciudad de Soria había conseguido mantenerse como una instancia a tener en cuenta en el escenario político regional, en el que no se vio reducida a la impotencia frente a los nobles que la rodeaban. Caso muy distinto fue el de las ciudades realengas riojanas, que ejercían la jurisdicción sobre tér-

109 DíAZ De Durana, José Ramón: «Las luchas de bandos: Ligas nobiliarias y enfrentamientos banderizos en el nordeste de la Corona de Castilla», en Conflictos sociales, políticos e intelectuales en la España de los siglos XIV y XV. XIV Semana de estudios de Nájera 2003, Instituto de Estudios Riojanos, Logroño, 2004, pp. 104 y ss. 
minos muy reducidos, y a fines de la Edad Media seguían sin haber adoptado un régimen de gobierno de claro carácter oligárquico, puesto que los oficiales se renovaban todos los años, y se reclutaban tanto entre los hidalgos como entre los pecheros. Estos rasgos los compartían con las ciudades de las provincias vascongadas, pero éstas fueron más afortunadas en su lucha contra la alta nobleza, entre otras razones porque las bases en que se sustentaba el poderío de ésta no eran tan firmes como aquéllas en que se apoyaban los grandes linajes riojanos.

Confiamos en que el presente trabajo haya servido al menos para dejar demostrada esta última aseveración, y en que estas reflexiones con que lo estamos concluyendo permitan tomar conciencia sobre la necesidad de realizar estudios comparativos acerca de la estructuración de las sociedades políticas en las distintas regiones de la Corona de Castilla hasta el fin del Antiguo Régimen, que sin duda habrán de contribuir a hacernos percibir de una forma menos distorsionada las situaciones del presente, contempladas por amplios sectores de la población únicamente desde la perspectiva interesada de los partidos políticos y de los medios de comunicación afines a ellos. 